\title{
LOS REGISTROS PÚBLICOS DE BENEFICIARIOS FINALES EN ARGENTINA: AVANCES Y RETROCESO DE UN PROCESO INCONCLUSO ${ }^{1}$
}

\author{
BENEFICIAL OWNERSHIP REGISTRIES IN ARGENTINA: PROGRESS AND SETBACKS OF \\ AN UNFINISHED PROCESS
}

\section{María Eugenia Marano}

\begin{abstract}
Abogada. Postgraduada en derecho de la empresa. Diplomada en criminalidad económica. Diplomada en género y derecho de la mujer. Consultora de Fundación SES. Redactora de artículos e investigaciones relacionadas a las personas jurídicas y a la identificación y prevención de la criminalidad económica.

E-mail: maria.eugenia.marano@gmail.com
\end{abstract}

Convidada

RESUMEN: El objetivo del presente trabajo es analizar la importancia y necesidad de contar con información precisa y actualizada de los reales beneficiarios finales de las personas y estructuras jurídicas. Su llegada a la legislación nacional y al derecho societario. Evolución del concepto. Relación con la criminalidad económica. Sujetos obligados a recabar información, modo en que lo hacen. Organismo de control y registro. El beneficiario final en la práctica. El beneficiario final en las sociedades extranjeras. Que ocurre con los llamados "testaferros". El Registro nacional de sociedades. Conclusiones, avances y retrocesos.

Palabras-clave: Beneficiario final; legislación; Umbral.

ABSTRACT: The objective of this working paper is to analyze the importance and relevance of accurate and updated information on the legal entities beneficial owners. Its arrival to the national legislation and company law. Concept evolution. Linkages to economic criminality. Entities bound by the obligation to report, and how they do it. Control and registry bodies. Beneficial ownership in practice. Beneficial ownership in foreign companies. What happens with the so called "front man". The National Companies Registry. Conclusions, progress and setbacks.

Keywords: Beneficial Ownership; legislation; threshold

SUMÁRIO: INTRODUCCIÓN; 1. La Unidad de Información Financiera; 2. La identificación del beneficiario final en la práctica; 2.1. El Banco Central y las entidades financieras; 2.2. Organismos de fiscalización de personas jurídicas y registros públicos de comercio; 2.2.1 Inspección General de Justicia (IGJ); 2.2.2. Dirección de Personas Jurídicas de la Provincia de Buenos Aires; 2.2.3. Inspección General de Justicia de Tierra del Fuego; 2.3 Registro Público de Estructuras Jurídicas: Contratos de Fideicomisos; 2.4 Comisión Nacional de Valores; 2.5 Superintendencia de Seguros de la Nación (SSN); 3. Las sociedades extranjeras; 4. El Registro Nacional de Sociedades; 5. Los beneficiarios finales y los testaferros; Conclusiones.

\footnotetext{
${ }^{1}$ El presente trabajo es parte integrante del documento elaborado por la autora y publicado originalmente por el Programa de Integración Regional y Financiamiento para el Desarrollo de Fundación SES - Preparado en el marco de la 5ta Conferencia Internacional sobre Registros públicos de beneficiarios finales de personas jurídicas y su vinculación con la corrupción, el lavado de activos y la evasión fiscal.
}

Revista de Direito Brasileira | Florianópolis, SC | v. 24 | n. 9 | p.222-249 | Set./Dez. 2019 


\section{INTRODUCCIÓN}

Ocultar la identidad de los verdaderos dueños de las empresas es una maniobra recurrente entre quienes buscan evadir impuestos, esconderse de los organismos de control, eludir a la justicia y dificultar investigaciones. Las acciones diseñadas para mantener fuera del alcance de las autoridades regulatorias la identidad de las personas humanas que, en última instancia, controlan las compañías facilita, en muchos casos, el lavado de dinero obtenido de actos ilícitos como la corrupción, el narcotráfico, la trata de personas y diversas violaciones de los derechos humanos. Las recientes megafiltraciones de información financiera dejaron al descubierto el extendido (ab)uso de complejas estructuras societarias. Panama Papers, Swiss Leaks, Paradise Papers, Bahamas Leaks o Luxleaks pusieron en evidencia la existencia de una industria dedicada a montar diversas estructuras societarias conformadas mediante entramados multijurisdiccionales que incluyen sociedades en guaridas fiscales ${ }^{2}$ y jurisdicciones opacas con el objetivo de ocultar la identidad de los verdaderos dueños de las empresas y explotar zonas grises en las legislaciones. Establecer leyes, regulaciones, normativas y mecanismos para recoger e intercambiar información sobre los "beneficiarios finales" de las empresas es condición necesaria para combatir los flujos financieros ilícitos.

El concepto del "beneficiario final" refiere al individuo o los individuos que, en última, instancia controlan o se benefician económicamente de una estructura jurídica. Los beneficiarios finales siempre serán personas humanas. A partir de las recomendaciones elaboradas por los organismos internacionales como el Grupo de Acción Financiera Internacional (GAFI) cada país establece su propia definición sobre quiénes son los "beneficiarios finales" así como los mecanismos sobre qué información recolecta, cómo se realiza el proceso y dónde almacena la información referida a los verdaderos dueños de las sociedades. El GAFI define al beneficiario final como aquella(s) persona(s) natural(es) que finalmente posee o controla a un cliente y /o a la persona física en cuyo nombre se realiza una transacción. Incluye también a las personas que ejercen el control efectivo final sobre una persona jurídica y otra estructura jurídica.

Los organismos como el GAFI ofrecen desde comienzos de los años noventa un conjunto de pautas y guías para que los países establezcan los procedimientos necesarios para garantizar su cumplimiento de la manera más certera posible. A pesar de las sucesivas modificaciones y actualizaciones introducidas a lo largo de las últimas tres décadas, las recomendaciones del organismo sostienen que "los países deben tomar medidas para impedir el uso indebido de las personas jurídicas para el lavado de activos o el financiamiento del terrorismo. Los países deben asegurar que exista información adecuada, precisa y oportuna sobre el beneficiario final y el control de las personas jurídicas, que las autoridades competentes puedan obtener o a la que puedan tener acceso oportunamente...".

Kenia, Uruguay, Sudáfrica, Costa Rica, Alemania, Ucrania, Dinamarca, Lituania y el Reino Unido son algunos de los países que cuentan con registros de beneficiarios finales de las empresas. Los listados no siempre están disponibles para ser consultados por el público y tampoco está garantizada la verificación de la información, pero las iniciativas facilitan que las autoridades fiscales y judiciales identifiquen a los verdaderos dueños detrás de las complejas y opacas estructuras montadas a través de distintas guaridas fiscales por las compañías que operan en sus territorios. El relevamiento realizado para esta investigación revela que Argentina no cuenta con

\footnotetext{
${ }^{2}$ Los guaridas fiscales, conocidas erróneamente como "paraísos fiscales", son territorios que permiten a personas humanas y jurídicas eludir normas, leyes y regulaciones. Entre las características que exhiben esas jurisdicciones se destaca la baja o nula tributación que, mediante normas específicas internas, garantizan la opacidad de las transacciones, con la ausencia absoluta de registros, formalidades y controles. El elevado grado de opacidad impide estimar las fortunas que se administran a través de la red global de guaridas fiscales. Otra característica particular es la extraterritorialidad, refiere a que el objeto no puede cumplirse dentro de la jurisdicción de origen.
}

Revista de Direito Brasileira | Florianópolis, SC | v. 24 | n. 9 | p.222-249 | Set./Dez. 2019 
ningún registro centralizado y la información existente se encuentra fragmentada y desactualizada en las distintas provincias y organismos de control que, en contadas ocasiones, requieren la información relativa a los beneficiarios finales de las empresas.

La figura del "beneficiario final" se introdujo en la legislación argentina en 2011 con la reforma de la Ley de Encubrimiento y Lavado de Activos de origen delictivo ${ }^{3}$. La medida tuvo lugar después de una evaluación realizada por el Grupo de Acción Financiera Internacional (GAFI) donde el organismo estableció que el país se encontraba en una suerte de "lista de gris". La evaluación del GAFI señalaba un conjunto de incumplimientos normativos en materia de delitos económicos de acuerdo con sus estándares que las autoridades argentinas buscaron subsanar mediante la incorporación de instrumentos que ampliaron los conceptos referidos a la prevención del lavado de activos y financiamiento del terrorismo.

En otras palabras, hasta 2011 la legislación y normativa argentinas no contemplaban la figura de los "beneficiarios finales". No se trataba solamente de la ausencia de la definición legal sobre quiénes son los verdaderos dueños de las empresas y otras estructuras societarias, sino que el marco regulatorio argentino, como muchos otros alrededor del mundo, carecía de mecanismos para recabar esa información fundamental para el control de los flujos financieros ilícitos. La figura del beneficiario final fue definida de una manera laxa lo que la tornaba de imposible cumplimiento en la práctica. Sólo debía identificarse al beneficiario final cuando existían interrogantes respecto de la actuación del cliente y, en especial, cuando estos lo hacían en nombre de terceras personas. Por ello con el objetivo de evitar que personas físicas utilicen a las personas jurídicas como empresas pantalla para realizar operaciones, se impuso que los sujetos obligados ${ }^{4}$ debían prestar especial atención ante ese tipo de situaciones y se les exigió verificar la conformación de las estructuras societarias a fines de determinar el origen de los fondos e identificar a los reales propietarios, beneficiarios y/o quienes ejercían el verdadero control sobre la persona y/o estructura jurídica. $^{5}$

La incorporación normativa utilizó como referencia las recomendaciones realizadas por el GAFI a sus miembros. Con el correr de los años, los organismos de control de Argentina fueron armonizando sus normas internas en línea con las recomendaciones, de tal modo se delineó la versión local del concepto. Desde entonces, se entiende al beneficiario final como la o las personas humanas que tengan como mínimo el $20 \%$ del capital o de los derechos de voto de una persona jurídica. Y, cuando ninguna de esas opciones fuera posible de identificar, la legislación indica que es necesario determinar a quiénes, por otros medios, ejercen el control final, directo o indirecto sobre una persona jurídica.

Los distintos organismos de control registraron ampliaciones, adaptaciones o modificaciones sobre la figura los beneficiarios finales que apuntaron a mejorar su identificación en algunos sectores. A partir de 2017 la Unidad de Información Financiera (UIF) ${ }^{6}$ amplió el concepto para las entidades financieras. La medida pretende abordar la complejidad advertida en la identificación del beneficiario final por el porcentaje de tenencias o por el ejercicio del control, agregando que en caso de no poder determinarse debe identificarse a la máxima autoridad del órgano de administración de la persona y/o estructura jurídica.

\footnotetext{
${ }^{3}$ La ley 25.246, sancionada el 13 de abril del año 2000, fue reformada por la ley 26.683 sancionada el 21.06.2011.

${ }^{4}$ Son las Personas Físicas y Jurídicas y Organismos del Estado, señaladas en el artículo 20 de la Ley № 25.246 y modificatorias. Los sectores determinados en dicho artículo son aquellos que los legisladores consideraron vulnerables para el Lavado de Activos y la Financiación del Terrorismo o bien que puedan recabar información de aquellos sujetos obligados considerados vulnerables. Ejemplo de ellos son: Los organismos de control y registro de personas jurídicas, la Comisión Nacional de Valores, las entidades financieras, los escribanos público, los contadores, el Registro de la propiedad inmueble, el registro de la propiedad automotor, entre otros.

${ }^{5}$ Véase Art. 21 ap. c) Ley 25.246.

${ }^{6}$ Resolución UIF 30-E-/2017, incorpora la posibilidad de identificar a las máximas autoridades de la persona jurídica como beneficiario final.
} 
En la misma dirección, la modificación a la Ley 25.246 a través del decreto presidencial $27 / 2018$ de enero de $2018^{7}$ y la Ley 27.444 , incorpora el concepto de beneficiario final en la legislación de fondo. Se reformuló y amplió el concepto que existía en Argentina del beneficiario final hasta la fecha. La nueva legislación incorpora la obligación de identificar a quienes ejerzan la administración y/o sean la máxima autoridad de la empresa en aquellos casos en los que no logre ser identificado por otros medios e introduce también el concepto de "patrimonio de afectación", aunque patrimonio está subsumido dentro de las estructuras jurídicas ya previstas.

Actualmente la legislación y normativa argentina identifica a los verdaderos dueños utilizando una prueba en cascada, (no como opciones alternativas) y en el siguiente orden:

Los verdaderos dueños son las personas humanas que:

1) son propietarias y/o beneficiarios finales, titulares del capital;

2) o que, ejerzan el control de la persona, estructura jurídica o patrimonio de afectación, aun cuando éste fuera indirecto;

3) a quienes posean facultades de administración y/o disposición, máxima autoridad de la persona y/o estructura jurídica.

La legislación establece que los beneficiarios finales siempre deben ser personas humanas, una persona jurídica no podría cumplir ese rol. La persona humana puede no coincidir con la persona del socio o accionista y/o parte de la persona y/o estructura jurídica, esto explica el ejercicio del control indirecto.

Asimismo y a los fines de definir quién es el propietario o titular de capital, las naciones establecen un umbral, es decir, un parámetro mínimo para determinar a partir de qué cantidad de tenencia podemos considerar a una propietario beneficiario final. En el caso de la Argentina, el umbral establecido por la Unidad de Información Financiera es del 20\% y utiliza para su identificación la prueba en cascada.

¿Cómo funciona una prueba en cascada? Cuando ninguna persona alcanza a ostentar el $20 \%$ del capital se pasa a la segunda opción y se debe buscar quién tiene el control por otros medios -derechos de voto o a través de un familiar, o ejerce algún tipo de influencia-. Si de ese modo tampoco puede identificarse, entonces se informarán los datos de la persona humana que ocupa el máximo cargo en la administración.

Vale señalar que esa información es recabada por los mismos integrantes de la empresas, el personal de la compañía o bien profesionales contratados por la misma a los fines de conocer a su cliente o bien presentar la información de los beneficiarios finales ante los Organismos que correspondan.

La nueva definición representa un avance y permite ahondar en la búsqueda de los reales beneficiarios finales. Sin embargo, presenta una serie de problemas que aún no se han resuelto y deberán ser abordados en las normas reglamentarias, las que deberán definir los límites y modalidades al concepto citado. El principal inconveniente es el umbral del 20\%, es muy elevado y por ende resulta fácil de eludir. Poder identificar al beneficiario final con un umbral más bajo facilita la identificación de los verdaderos dueños, ello por cuanto, fijar un piso elevado les permitirá dividir sus tenencias de manera más sencilla para evitar ser individualizados. Otra forma extendida para ocultar al beneficiario final es la del testaferro, ha sido un avance la reciente reforma a la Ley general de Sociedades que prohibió el uso de las figuras "socio del socio" y "socio oculto", conocidos también como prestanombres o testaferros en las sociedades comerciales.

Pero incluso si se resuelven los desafíos referidos a la definición del concepto en la legislación, la identificación de los beneficiarios finales de las empresas en Argentina está condicionada por la fragmentación, desactualización y ausencia de verificación de los registros

\footnotetext{
${ }^{7}$ Decreto del PEN nº 27/2018 denominado de "Desburocratización y Simplificación", fue un decreto ómnibus dictado
} el 11.01.2018 mediante el cual se reformaron muchas leyes del cuerpo normativo de nuestro país.

Revista de Direito Brasileira | Florianópolis, SC | v. 24 | n. 9 | p.222-249 | Set./Dez. 2019 
provinciales así como aquellos que llevan los distintos organismos de control. Este trabajo se propone analizar los avances y limitaciones que exhiben los principales registros encargados de establecer los lineamientos y recabar la información referida los beneficiarios finales. Este trabajo está dividido en seis partes. La primera analiza el desempeño de la Unidad de Información Financiera (UIF) en la definición del concepto de los beneficiarios finales como órgano rector y autoridad de aplicación en materia de prevención del lavado de activos y financiamiento del terrorismo. En el segundo apartado se analiza cómo los distintos sujetos obligados ponen en práctica las pautas establecidas por la UIF referidas a la identificación de los beneficiarios finales de las empresas. El apartado analiza los casos del Banco Central, la Inspección General de Justicia, la Superintendencia de Seguros de la Nación, la Comisión Nacional de Valores y las entidades financieras. El trabajo aborda además la recolección de información a cargo los organismos de fiscalización de personas jurídicas y los registros públicos de comercio provinciales con especial énfasis en los casos de la Inspección General de Justicia, Dirección de Personas Jurídicas de la Provincia de Buenos Aires y Inspección General de Justicia de Tierra del Fuego. El tercer apartado se enfoca en el Registro Nacional de Sociedades que todavía se encuentra en su etapa inicial. El cuarto apartado analiza los (ab)usos vinculados a las sociedades extranjeras, en particular aquellas emplazadas en guaridas fiscales y financieras, que son unos de los principales vehículos corporativos utilizados para ocultar la identidad de los verdaderos beneficiarios finales. El anteúltimo apartado está dedicado a la figura de los testaferros que también ha sido históricamente utilizada para ocultar a los reales dueños de las corporaciones. El trabajo finaliza con una serie de conclusiones que apuntan a señalar las dificultades que existen en Argentina a la hora de recabar la información necesaria y ofrece algunos lineamientos para comenzar a superar esas restricciones.

\section{LA UNIDAD DE INFORMACIÓN FINANCIERA}

La UIF es el organismo encargado del análisis, el tratamiento y la transmisión de información a los efectos de prevenir e impedir el delito de lavado de activos y financiamiento del terrorismo ${ }^{8}$. Tiene la obligación de dictar normas y procedimientos de alcance a los sujetos obligados. Es decir, la UIF está encargada de regular a todos los organismos, personas humanas y personas jurídicas obligadas a reportar la detección de cualquier operación sospechosa de estar lavando activos y/o financiando el terrorismo. Entre quienes están alcanzados por la normativa de la UIF figuran, por ejemplo, los escribanos, los contadores, las sociedades que cotizan en la bolsa, las entidades financieras, las empresas que se dedican a la compra venta de joyas así como los organismos de la Administración Pública que ejerzan funciones de control y fiscalización de personas jurídicas, entre otros ${ }^{9}$.

Las normas de la UIF ofrecen las herramientas conceptuales para que cada uno de los sujetos obligados dicte las normas internas en caso de considerarlo necesario $\mathrm{y}$, cuando no fuera así, establece que sus acciones deberán regirse por la normativa del organismo. Una parte importante de sus funciones reside en reglamentar (o bien fijar) pautas objetivas, para cada uno de los sujetos obligados o todos en general respecto de aquello que la ley de fondo les impone. Tal es el caso de la resolución UIF n 29/2011 para los Registros Públicos, la resolución UIF n²1/2018 para los sujetos obligados del mercado de capitales, la resolución 30-E/2017 para las entidades financieras, entre otras. Cada una de dichas normas tiene en cuenta la operatoria específica de cada sujeto y en virtud de ello elabora una guía de procedimiento para la prevención del lavado de activos, la identificación de operaciones sospechosas, la identificación del beneficiario final, etc.

\footnotetext{
${ }^{8}$ La UIF fue creada en el año 2000 y funciona con autonomía y autarquía financiera. Hasta el 26 de mayo de 2016 bajo jurisdicción del Ministerio de Justicia y Derechos Humanos de la Nación. En el año 2016 pasó a estar bajo la órbita del Ministerio de Finanzas, actual Ministerio de Hacienda.

${ }^{9}$ El listado de sujetos obligados está formulado en el Artículo 20 de la Ley 25.246.
}

Revista de Direito Brasileira | Florianópolis, SC | v. 24 | n. 9 | p.222-249 | Set./Dez. 2019 
Las primeras normas que incorporan dentro de sus definiciones la figura del Beneficiario Final datan de 2011. Antes de esa legislación no fue posible hallar norma alguna que refiera expresamente a los beneficiarios finales. A partir de 2011, las pocas normas que mencionaban al beneficiario final lo hacían en su glosario de definiciones y de manera repetida consideraban al Propietario/Beneficiario: como aquella persona física que tenga como mínimo el $20 \%$ del capital o de los derechos de voto de una persona jurídica o que por otros medios ejerza el control final, directo o indirecto sobre una persona jurídica. ${ }^{10}$

A partir del año 2017, la UIF amplió el concepto de beneficiario final y dispuso opciones para su determinación, es decir frente a la imposibilidad de encontrar al beneficiario final incorpora una serie de posibilidades que permiten identificar como beneficiario final a otros sujetos, por ejemplo, a las máximas autoridades societarias, dedicándole artículos específicos y una especial atención.

Tal es el caso de la Resolución 30-E de la UIF dictada para las entidades financieras, sin embargo y desconociendo los motivos muchas de las resoluciones de UIF dictadas para otros sujetos no fueron modificadas en tal sentido, es decir, que aún mantienen el concepto de beneficiario final de 2011. Tarea pendiente para la Unidad de Información Financiera.

No obstante, siendo que la ley especial $n^{\circ} 25.246$ amplio el concepto ${ }^{11}$, todos aquellos sujetos que en su normativa interna definen al beneficiario final podrán adoptar la definición allí dispuesta o bien la utilizada por la UIF para otros sujetos tal como lo hizo la Dirección de Personas Jurídicas de la Provincia de Buenos Aires adoptando la definición prevista en la Resolución 30-E de 2017.

La UIF no lleva ningún Registro de Beneficiarios Finales, sólo se limita a solicitar información a los organismos públicos encargados de recabar información de los beneficiarios finales de aquellos sujetos que se encuentren bajo su órbita de competencia por ejemplo en el marco de una investigación nacida de un Reporte de Operación Sospechosa (ROS). Por ejemplo, el Registro de la Propiedad Inmueble envía un ROS a la UIF cuyo objeto es la solicitud de inscripción de un inmueble adquirido por una sociedad extranjera registrada en la Inspección General de Justicia por una suma muy elevada de dinero, frente a ello y con el inicio de un sumario administrativo, la UIF podrá solicitar información a dicho organismo sobre el funcionamiento de dicha entidad, la composición de su capital social y sus beneficiarios finales y/o cualquier dato que le organismo de registro le pueda brindar. La información que suministren los organismos dependerá del tipo y calidad de los registros que mantenga cada uno sobre los beneficiarios finales de las empresas.

\section{LA IDENTIFICACIÓN DEL BENEFICIARIO FINAL EN LA PRÁCTICA}

El siguiente apartado ofrece un análisis de la situación en la que se encontraban a mediados de 2019 los principales organismos en materia de personas y estructuras jurídicas, respecto de la recolección de información de los beneficiarios finales. Los organismos analizados a continuación no fueron seleccionados al azar, sino que se tuvieron en cuenta tres criterios. En primer lugar, su doble rol ante la UIF. Por un lado, integran el listado de sujetos obligados y, por lo tanto, deben contar con un oficial de cumplimiento a los fines de reportar aquellas operaciones sospechosas y/o pasibles de estar encubriendo maniobras para el lavado de activos y/o el financiamiento del terrorismo. Y, por el otro, son sujetos colaboradores del organismo de manera que deben contar un oficial de enlace encargado de remitir toda la información que la UIF le solicite. Para cumplir con dicha función los organismos debe llevar registros certeros y actualizados de las personas físicas

\footnotetext{
${ }^{10}$ Por ejemplo: Resolución UIF 30/2011(Personas Jurídicas que reciben donaciones) Art. 2 inc g. Resolución 229/2011 (Mercado de Capitales) art. 2 inc g. Resolución UIF 140/2012(Fideicomisos). Art. 2 inc i. , Resolución 22/2011 (CNV) art 2 inc f., entre otros.

${ }^{11}$ Art. 21 bis Ley 25.246 modificada por Ley 27.446 del 18/06/2018.
}

Revista de Direito Brasileira | Florianópolis, SC | v. 24 | n. 9 | p.222-249 | Set./Dez. 2019 
y/o jurídicas que se encuentran bajo su órbita de competencia. Como así también desarrollar procesos y mecanismos que permitan prevenir maniobras de lavado de activos y financiamiento del terrorismo, entre los que se encuentran la identificación y registro de los beneficiarios finales.

El segundo criterio contemplado al momento de definir cuáles organismos serían abordados fue el caudal de personas y estructuras jurídicas que se registran y sobre las cuales se lleva o debería llevarse control y registro de beneficiarios finales. En tercer lugar, se tuvo en cuenta la existencia de una normativa en materia de identificación de los beneficiario final.

\subsection{El Banco Central y las entidades financieras}

Las primeras normas dictadas por UIF, en el año 2000 estuvieron vinculadas al funcionamiento del sistema financiero y, por lo tanto, alcanzan al Banco Central y las entidades financieras. La Carta Orgánica del BCRA establece que la finalidad principal del organismo es la de promover la estabilidad del sistema financiero, del empleo y el desarrollo económico de la Nación. Para ello, dentro de sus funciones y facultades se encuentran las de regular el sistema financiero nacional, de aplicar la Ley de Entidades Financieras ${ }^{12}$, contribuir al buen funcionamiento del mercado de capitales y a la protección de los derechos de usuarios de servicios financieras. Para garantizar el cumplimiento de tales obligaciones, el BCRA cuenta con la Superintendencia de Entidades Financieras. Asimismo, la autoridad monetaria es el organismo encargado de autorizar y otorgar las condiciones de funcionamiento a las entidades públicas y privadas, nacionales y extranjeras dedicadas a la actividad financiera en la Argentina.

Los operadores del sistema financiero son quienes toman el primer contacto con las transacciones sospechosas o bien con la mayor cantidad de ellas y todos sus involucrados. Por lo tanto, resulta imprescindible que tales agentes cuenten con procedimientos efectivos para conocer a los beneficiarios finales, el BCRA respecto de las entidades financieras, y estas últimas respecto de sus clientes.

En tal sentido la UIF, como órgano encargado de dictar normas, siempre ha puesto especial atención y ha priorizado las relacionadas con las entidades financieras. Un claro ejemplo de ello fue el dictado de la Resolución 30-E/2017, dedicada exclusivamente a las entidades financieras, la que amplió el concepto de beneficiario final, incorporando la posibilidad de identificar a la máxima autoridad de la persona jurídica. La norma define distintas formas de acreditar la identificación del beneficiario final por parte de los clientes personas jurídicas, sin embargo la definición no es contundente.

La redacción de la normativa resulta un tanto laxa ya que pareciera indistinto que, al momento de identificar a los beneficiarios finales, los bancos requieran una declaración jurada, una copia de los registros de accionistas y cualquier documentación o información pública que identifique la estructura de control. Aunque avanza en la identificación de los verdaderos dueños, la normativa comete un error al igualar a los accionistas con los beneficiarios finales que no necesariamente podrán ser la misma persona.

Pedir información de manera tan amplia, sin un orden de prelación corre el riesgo de no ser certera. Además de ello, la norma establece que las sociedades que cotizan en bolsa quedarán exceptuadas de los requisitos de identificación. Esa excepción no resulta acertada atento a que no existen herramientas que permitan cruzar los datos entre los distintos organismos de control. Sería oportuno que tanto el Banco Central, respecto de las entidades financieras, como las entidades financieras respecto de sus clientes -ya sea que coticen o no en la bolsa- lleven un registro de beneficiarios finales.

Una revisión exhaustiva de la regulación vigente no permitió hallar normas, circulares o resoluciones internas del BCRA que reglamenten el modo y forma exigidas para la presentación

${ }^{12}$ Véase Ley de Entidades Financieras no 21.526.

Revista de Direito Brasileira | Florianópolis, SC | v. 24 | n. 9 | p.222-249 | Set./Dez. 2019 
de la información de los beneficiarios finales de las entidades financieras que pretendan operar en nuestro país, se rigen solo por la normativa de la UIF. El BCRA no cuenta con un Registro de Beneficiarios Finales de las entidades financieras bajo su órbita de competencias (casas de cambio, bancos, cajas cooperativas de crédito), como así tampoco las entidades financieras respecto de sus clientes (empresas de todo tipo).

Consultas realizadas ante distintas entidades financieras revelaron que solicitan a sus clientes personas jurídicas completar una planilla con información respecto de sus beneficiarios finales al inicio de la relación comercial aunque, salvo contadas excepciones, la información no se actualiza (ver Figura 1). Los datos sólo quedan registrados en el legajo del cliente y no son cruzados con información del resto de los clientes. Todo ello impide oportunidades de detectar operaciones sospechosas y maniobras delictivas que pretenden ocultar a los reales beneficiarios finales.

Con un registro unificado de beneficiarios finales se podría identificar de cuantas entidades financieras es beneficiaria final una misma persona y en qué porcentaje, lo mismo respecto de los clientes de las entidades financieras ello de acuerdo a las inusualidades tipificadas por la UIF permitiría advertir operaciones sospechosas de lavado de activos.

\subsection{Organismos de fiscalización de personas jurídicas y registros públicos de comercio}

La Constitución Nacional argentina establece en su Artículo 121 que las provincias conservan todo el poder no delegado al Gobierno federal. En otras palabras, las jurisdicciones subnacionales mantienen todos los derechos de organizar y dictar sus normas de procedimientos en todos los ámbitos que no fueron delegados a la Nación. Entre ellas se encuentran los registros de personas jurídicas y los organismos de control y fiscalización. Cada una de las 24 provincias argentinas se encuentra entonces organizada de manera diferente y con normas de procedimiento distintas.

Algunas jurisdicciones cuentan con ambos organismos unificados; es decir, cumplen el doble rol de fiscalización y registro. En ese grupo figuran, por ejemplo, la Inspección General de Justicia cuyo ámbito de competencia es la Ciudad Autónoma de Buenos Aires ${ }^{13}$, la Dirección de Personas Jurídicas para la Provincia de Buenos Aires, la Inspección General de Justicia de Tierra del Fuego y la Dirección de Inspección de Personas Jurídicas de Córdoba. En cambio, en otras provincias las funciones de fiscalización y registro se encuentran desdobladas. Salta, Chubut, San Juan y Misiones, son algunas de las provincias que cuentan con un registro público de comercio y una inspección general de personas jurídicas a cargo de la fiscalización.

De las veinticuatro provincias argentinas, catorce tiene sus competencias unificadas en un organismo y las otras diez las tienen desdobladas. Conforme ello, el país cuenta así con un total de 36 organismos de registro y control de personas jurídicas. Ello implica una dispersión normativa y de criterios muy amplia que impide armonizar la información que podría reunirse en un sólo registro. A la dispersión se suma la falta de digitalización de los datos obtenidos impidiendo el entrecruzamiento, publicidad, acceso y verificación de la información referida a los beneficiarios finales de las empresas.

De los 34 organismos de registro y control de personas jurídicas, sólo tres 3 cuentan con una definición sobre beneficiarios finales y mantienen un registro en soporte papel. En ese escenario se vuelve imposible avanzar hacia la creación de un registro nacional de beneficiarios finales o bien que dicha información sea remitida al flamante Registro Nacional de Sociedades y de ese modo contar con información precisa, actualizada y completa sobre los beneficiarios finales de las entidades inscriptas en todo el país.

A la falta de sistematización normativa y de la información se suma el hecho que el alcance en el control de legalidad y la consecuente solicitud de información que pueden efectuar

${ }^{13}$ Con excepción de las sociedades de capitalización y ahorro en cuyo caso el alcance es nacional. Revista de Direito Brasileira | Florianópolis, SC | v. 24 | n. 9 | p.222-249 | Set./Dez. 2019 
los registros públicos y los organismos de fiscalización dependerá del tipo societario. Por ejemplo, las sociedades anónimas (SA) están sujetas a un control estricto por parte de los organismos de control de personas jurídicas y deben cumplir con ciertas obligaciones ante los registros públicos como la presentación anual de estados contables, inscripción de la renovación de autoridades. Vale señalar que toda esa información es presentada por las empresas cada tres años (como máximo). Ello no ocurre con las sociedades de responsabilidad limitada (SRL) o las sociedades extranjeras. Tales precisiones y alcance surgen de la Ley General de Sociedades.

Lo mismo ocurre con las sociedades por acciones simplificadas (SAS) cuyas obligaciones y actos que se deben registrar en el organismo de fiscalización y control surgen de la Ley de Apoyo al Capital Emprendedor. La oportunidad para recabar información sobre el beneficiario final se encuentra íntimamente ligada a las obligaciones que deben cumplir los diferentes tipos societarios (S.A., S.R.L., Sociedades Extranjeras, U.T.E, S.A.S, etc) de acuerdo a su legislación de fondo.

\subsubsection{Inspección General de Justicia (IGJ)}

La IGJ recaba información de los beneficiarios finales de las personas jurídicas en el ámbito de la Ciudad Autónoma de Buenos Aires desde el año $2015^{14}$ cuando incorporó por primera vez a su normativa un capítulo dedicado a la prevención del lavado y financiamiento del terrorismo. Desde entonces utiliza la definición de beneficiario final suministrada por la UIF: "Personas Humanas que tengan como mínimo el 20\% (umbral variable) del capital o de los derechos de voto de una persona jurídica o que por otros medios ejerzan el control final, directo o indirecto sobre una persona jurídica u otra estructura jurídica".

Esa información deben brindarla las sociedades nacionales, binacionales, sociedades constituidas en el extranjero y/o de registración o modificación de contratos asociativos o contratos de fideicomiso ${ }^{15}$. En el caso de los contratos de fideicomiso, cuyo objeto sean cuotas sociales o acciones, se deberá individualizar al/los beneficiario/s final/es del fiduciante, fiduciario y, si estuvieren determinados, del beneficiario y fideicomisario. En el supuesto de los contratos asociativos -uniones transitorias de empresas o acuerdo de colaboración empresaria-, se deberá individualizar al/los beneficiario/s final/es de las entidades que integran el contrato.

La declaración jurada debe presentarse una vez por año calendario en la primera oportunidad en que se solicite la inscripción de alguno de los trámites registrales previstos en la normativa del organismo, siendo suficiente en los trámites posteriores que se efectúen dentro del mismo año calendario acreditar su cumplimiento anterior mediante copia simple de la misma. En caso de no efectuarse ninguna presentación durante todo un año calendario, deberá cumplirse con las declaraciones juradas adeudadas en la primera oportunidad en que se solicite la inscripción de alguno de los trámites registrales referidos en el primer párrafo del presente artículo.

La presentación de la declaración jurada de Beneficiario Final comienza online mediante un aplicativo web que, una vez completado, genera un archivo con formato PDF de la declaración. Ese archivo debe imprimirse, suscribirse y presentarse junto con el trámite del cual se pretende su inscripción.

La hoja contiene en la parte inferior un código de barras único que opera como comprobante del envío de la información vía web. Dicho código de barras, tras un lustro de su inclusión, todavía no impacta en ningún registro digital de beneficiarios finales. Y, a pesar de contar con la posibilidad de avanzar en la digitalización, el único registro que mantiene la IGJ es en soporte papel.

La declaración jurada debe presentarse con firma del propio Beneficiario Final o de Representante Legal y certificado por Escribano o Dictaminante, y deberán indicarse datos personales completos del beneficiario final (nombre y apellido, número de DNI, número de CUIT,

\footnotetext{
${ }^{14}$ A partir de la Resolución General IGJ 7/2015

${ }^{15}$ Artículo 518 del Anexo "A" de la Resolución General I.G.J. N 07/2015
}

Revista de Direito Brasileira | Florianópolis, SC | v. 24 | n. 9 | p.222-249 | Set./Dez. 2019 
domicilio real, nacionalidad, fecha de nacimiento, profesión y porcentaje de participación que directa o indirectamente posea en la entidad) y datos completos de la persona jurídica (denominación, número de registro en la IGJ, tipo societario y número de CUIT).

Lo mismo ocurre con la normativa de las Sociedades por acciones simplificadas, incorporadas al ordenamiento jurídico argentino en el año 2017 y reglamentada por la IGJ mediante la Resolución IGJ 6/2017.

Es dable destacar que la presentación de dicha información es requisito para la inscripción de los trámites, por lo que si bien no existen sanciones expresas ante el incumplimiento, de no presentarse la sociedad no podrá contar con su acto inscripto y por ello su operatoria comercial se podrá ver restringida.

Sin embargo, ante la declaración jurada que indica que la persona jurídica no cuenta con beneficiario final, no existe un real control sobre dicha información. En el caso de la IGJ existe la declaración Jurada de "no posee Beneficiario Final", lo que muchas veces no resulta ser tal. Siendo que este Organismo aún no adoptó la nueva definición de beneficiario Final, no resulta posible la identificación de la máxima autoridad del órgano de administración a los fines de cumplimentarlo.

Respecto de las sociedades extranjeras, previo al dictado de la Resolución 6/2018, las sociedades extranjeras también debían presentar la declaración jurada de beneficiario final en oportunidad del cumplimiento obligatorio del régimen informativo anual, mediante tal acto informaban también la composición accionaria del capital. Al dictarse la mencionada resolución dicha obligación fue suprimida.

Asimismo cabe agregar que la IGJ lleva un registro de sociedades inactivas. Las mismas fueron detectadas como tales luego de un proceso de reempadronamiento. Si bien ello permitió conocer el estado de muchas empresas también dejó al descubierto la cantidad de empresas que se constituyen y luego no presentan movimientos. Detrás de tales sociedades también se esconden reales beneficiarios y no contamos con información sobre ello.

\subsubsection{Dirección de Personas Jurídicas de la Provincia de Buenos Aires}

La Dirección de Personas Jurídicas de la Provincia de Buenos Aires (DPJ), es el organismo encargado de la fiscalización y registro de las personas y estructuras jurídicas que tiene su domicilio en esa jurisdicción. La DPJ incorporó a su normativa la figura del beneficiario final en $2017^{16}$. Entonces, la dirección bonaerense receptó un concepto más amplio de beneficiario final, siendo el primer organismo de registro de personas jurídicas del país en incorporar la posibilidad de identificar y/o denunciar a la máxima autoridad societaria en caso de que no se pueda identificar al beneficiario real.

La DPJ entiende al Beneficiario Final como “(...) toda persona humana que controla o puede controlar, directa o indirectamente, una persona jurídica o estructura legal sin personería jurídica, y/o que posee, al menos, el $20 \%$ del capital social o del derecho de voto, o que por otros medios ejerce su control final, de forma directa o indirecta. Cuando no sea posible identificar a una persona humana deberá identificarse y verificarse la identidad del presidente, representante legal o la máxima autoridad que correspondiere. En el caso de los contratos de fideicomiso, se deberá individualizar al/los beneficiario/s final/es del fiduciante, fiduciario $\mathrm{y}$, si estuvieren determinados, del beneficiario y fideicomisario. En el supuesto de los contratos asociativos, se deberá individualizar al/los beneficiario/s final/es de las entidades que integran el contrato".

En cuanto a la oportunidad coincide con la prescripta por la IGJ, deberá realizarse a través de una declaración jurada en todos los trámites registrales efectuados por sociedades nacionales, binacionales, sociedades constituidas en el extranjero y/o de registración o modificación de contratos asociativos o contratos de fideicomiso. La forma de presentar esa información es bajo la

${ }^{16}$ Disposición General n 130 /2017 del 22/12/2017. 
modalidad de declaración jurada, indicando datos personales completos de la persona que revista el carácter de beneficiario/s final/es. En tal declaración deberá informar: Nombre y apellido, DNI, domicilio real, estado civil, nacionalidad, profesión y porcentaje de control), y ofrece las siguientes alternativas de presentación:

a) Declaración Jurada de Beneficiario Final con firma certificada del propio beneficiario final declarante; o,

b) Declaración Jurada de Beneficiario Final con firma certificada del representante legal en el caso de sociedades o contratos asociativos o firma certificada del Fiduciario en el Contrato de Fideicomiso.

c) Cuando se trate de la constitución de una sociedad comercial por escritura pública, mediante la manifestación expresa, en la escritura pública de constitución, del escribano público autorizante de que, por ante él, el/los beneficiarios finales o el representante legal manifestaron con carácter de declaración jurada que revisten la calidad de tales o bien informan quien o quienes resulten ser el/los beneficiario/s finales de la entidad.

d) En el caso de constitución de Sociedades por Acciones Simplificadas registradas a través de los módulos de Trámite a Distancia (TAD) y de Gestión de Documentos Electrónicos de la Provincia de Buenos Aires (GDEBA), la declaración jurada se presentará mediante respectivo formulario a través de TAD.

Otra característica particular de la norma bonaerense es que expresamente indica que el cumplimiento de la presentación de la mencionada declaración jurada es requisito indispensable para la aprobación de los actos sujetos al control de legalidad y registración de la Dirección Provincial de Personas Jurídicas. La Dirección de Personas Jurídicas no lleva un registro digital de los Beneficiarios finales, sólo recaba la información por tipo societario en soporte papel. Salvo en el caso de las Sociedades por Acciones Simplificadas cuyo registro integral se da de manera digital pero aún no se ha materializado una base de datos unificada de Beneficiarios Finales.

\subsubsection{Inspección General de Justicia de Tierra del Fuego}

La provincia de Tierra del Fuego incorporó la figura del beneficiario final en noviembre de 2018 de la mano de las normas de inscripción de las sociedades por acciones simplificadas. Siendo que el trámite de registro del mencionado tipo societario es netamente digital, uno de los campos a completar es del beneficiario final y dentro de la reglamentación los define como toda persona humana que tenga como mínimo el $20 \%$ del capital o de los derechos de voto de una persona jurídica o que por otros medios ejerzan el control final, directo o indirecto sobre una persona jurídica u otra estructura jurídica.

La declaración jurada deberá ser completada y suscripta por el representante legal, escaneada y subida a la plataforma digital de las sociedades por acciones simplificada como requisito para la constitución del trámite.

Recientemente fue incorporada la obligación de identificar a los beneficiarios finales para los restantes tipos societarios. La misma se en cada trámite de constitución, no así en los restantes trámites de la sociedad, y puede surgir del propio instrumento de constitución o bien mediante nota certificada por separado firmada por el propio beneficiario final. No se lleva un registro de beneficiarios finales sino que queda en el legajo de la propia sociedad. Tampoco cuento con una norma específica al respecto. ,

\subsection{Registro Público de Estructuras Jurídicas: Contratos de Fideicomisos.}


Las “estructuras jurídicas” refieren a aquellos contratos como el fideicomiso mediante el cual una parte, el fiduciante, transmite o se compromete a transmitir la propiedad de bienes a otra persona, denominada fiduciario, quien se obliga a ejercer el derecho de propiedad en beneficios de otra llamada beneficiario, que se designa en el contrato, para transmitirlo en última instancia ante el cumplimiento de determinado plazo a otra persona, denominada fideicomisario ${ }^{17}$. En otras palabras, una persona humana o jurídica afecta parte de su patrimonio a un negocio que será explotado por otra persona y cuyo beneficio lo obtendrá otra u otras personas humanas o jurídicas. Todas ellas identificadas en el contrato. Siendo que quien invierte el dinero puede ser o no el beneficiario del producido de dicho contrato, resulta necesario conocer a quienes son los verdaderos beneficiarios del negocio.

En la Argentina existen diversas clases de fideicomisos, de acuerdo el objeto que posean podrán ser de administración, de garantía, testamentarios, inmobiliarios, entre otros y se encuentran regulados en el Código Civil y Comercial de la Nación.

Esta figura ha sido y es muy utilizada para lavar dinero o bien para ocultar a los reales dueños o beneficiarios de negocios ilícitos, siendo que las partes pueden ser personas humanas o jurídicas. Por tal motivo resulta imprescindible obtener información de los beneficiarios finales de cada una de las partes integrantes del contrato.

En efecto, la ley de Encubrimiento y Lavado de Activos de origen delictivo le otorga calidad de sujetos obligados a las personas humanas o jurídicas que actúen como fiduciarios, en cualquier tipo de fideicomiso y las personas humanas o jurídicas titulares de o vinculadas, directa o indirectamente, con cuentas de fideicomisos, fiduciantes y fiduciarios ${ }^{18}$. La UIF también dedica una resolución particular expresa a los fideicomisos en la que incluye que deben identificar a los beneficiarios finales ${ }^{19}$.

Asimismo a partir de la reforma del Código Civil y Comercial de la Nación se dispuso que debían llevarse registro públicos de fideicomisos a excepción de aquellos cuyo objeto sean acciones o cuotas sociales los que continuarán registrándose en los registros públicos de comercio, actualmente llamados Registros públicos.

Puntualmente y respecto de los Registros públicos de fideicomisos o estructuras jurídicas, también cada provincia organiza su propio registro y dicta sus normas reglamentarias respecto de todos aquellos fideicomisos cuyo objeto no sean cuotas o acciones, en tales casos se registran en los registros públicos de comercio antes mencionados. En idéntico sentido que las personas jurídicas, estas estructuras deben estar reglamentadas y su normativa debe prever la identificación de los beneficiarios finales. Actualmente sólo existe información de los beneficiarios finales de los fideicomisos cuyo objeto son cuotas o acciones inscriptos en los tres registros públicos que cuentan con una definición y un procedimiento para la presentación de dicha información. Respecto de los restantes fideicomisos no es posible acceder a la información de los beneficiarios finales. Ello significa un retroceso importante y falta de todos aquellos Fideicomisos cuyo objeto no sean acciones o cuotas, los que deberán inscribirse en el Registro Público de Fideicomisos de la jurisdicción de que se trate.

Actualmente sólo se encuentra en funcionamiento el correspondiente a la Jurisdicción de la Ciudad Autónoma de Buenos Aires ${ }^{20}$, y dentro de los requisitos de registro no se encuentra nada respecto de la declaración del beneficiario final. (Resolución 227/2017 del Gobierno de la Ciudad de Buenos Aires).

\footnotetext{
${ }^{17}$ Véase art. 1666 Código Civil y Comercial de la Nación.

18 Véase art. 20 inc.22 Ley 25.246.

${ }^{19}$ Vease Resolución UIF 140/2011.

${ }^{20}$ Por Decreto N ${ }^{\circ}$ 300/2015 el Poder Ejecutivo del Gobierno de la Ciudad Autónoma de Buenos Aires estableció el Registro Público de Contratos de Fideicomiso.
} 
El GAFI también ha puesto especial atención en este tipo de contratos, refiriéndose a ellos en la recomendación $\mathrm{N}^{\circ} 25^{21}$. Que unos pocos registros cuenten con información sobre los beneficiarios finales de los fideicomiso significa un pequeño acercamiento al cumplimiento de la mencionada recomendación que exige a los países llevar información certera y actualizada de los beneficiarios finales de las partes que integran los fideicomisos, pero no cumple con el requisito esencial de solicitud de información del beneficiario final cuando podría hacerlo sin inconveniente. Se advierte falta de preocupación, capacitación y conciencia sobre el tema.

No existe un registro central, tal como ocurre con las personas jurídicas, cada jurisdicción deberá organizar su registro y por el momento sólo lo tiene la Ciudad de Buenos Aires para el caso de fideicomisos cuyo objeto no sean acciones o cuotas sociales. Pero sin perjuicio de ello, no recaban información sobre el beneficiario final. Si bien esto implica un retraso, un incumplimiento a las recomendaciones el GAFI, fundamentalmente las autoridades de regulación y control en Argentina se pierden la oportunidad de conocer quienes realmente se encuentran detrás del negocio jurídico cuando se utiliza esta figura para lavar y ocultar dinero y/o para ocultar a los reales beneficiarios.

\subsection{Comisión Nacional de Valores}

La Comisión Nacional de Valores (CNV) es el organismo encargado de la promoción, supervisión y control del Mercado de Capitales. Es una entidad autárquica que se encuentra bajo la órbita del Ministerio de Hacienda de la Nación Argentina. El mercado de capitales es el ámbito donde se ofrecen públicamente valores negociables $u$ otros instrumentos previamente autorizados para que, a través de la negociación por agentes habilitados, el público realice actos jurídicos, todo ello bajo la supervisión de la CNV. En este ámbito actúan diferentes entidades, las principales tienen la obligación de informar a los beneficiarios finales: estas son las emisoras y los agentes.

Las emisoras son aquellas entidades que colocan acciones (parte alícuota del capital social) con el fin de obtener recursos del público inversionista y pueden ser sociedades anónimas, el gobierno federal, instituciones de crédito o entidades públicas descentralizadas. Los agentes, por su parte, son personas humanas y/o jurídicas autorizadas por la CNV para su inscripción dentro de los registros correspondientes, para abarcar las actividades de negociación, colocación, distribución, corretaje, liquidación y compensación, custodia y depósito colectivo de valores negociables, las de administración y custodia de productos de inversión colectiva, las de calificación de riesgos, y todas aquellas que, a criterio de la $\mathrm{CNV}$, corresponda registrar para el desarrollo del mercado de capitales. La mayoría de los agentes reviste el carácter de persona jurídica por lo que están obligados a informar sobre su reales dueños.

La CNV cuenta con un importante plexo normativo dentro del cual se advierte la ausencia de un criterio unificado para identificar a los beneficiarios finales de las entidades y agentes. Por un lado, adopta las resoluciones dictadas por la UIF para aquellos sujetos obligados que se encuentran dentro de su órbita de competencia, y tal como lo identifica para otros Organismos los define como "toda persona humana que controla o puede controlar, directa o indirectamente, una persona jurídica o estructura legal sin personería jurídica, y/o que posee, al menos, el $20 \%$ del capital o de los derechos de voto, o que por otros medios ejerce su control final, de forma directa

\footnotetext{
${ }^{21}$ Recomendación n`25 del GAFI "Los países deben tomar medidas para prevenir el uso indebido de otras estructuras jurídicas para el lavado de activos o el financiamiento del terrorismo. En particular, los países deben asegurar que exista información adecuada, precisa y oportuna sobre los fideicomisos expresos, incluyendo información sobre el fideicomitente, fiduciario y los beneficiarios, que las autoridades competentes puedan obtener o a la que puedan tener acceso oportunamente.Los países deben considerar medidas para facilitar el acceso a la información sobre el beneficiario final y el control por las instituciones financieras y las APNFD que ejecutan los requisitos establecidos en las Recomendaciones 10 y 22. https://www.fatf-gafi.org/media/fatf/documents/recommendations/pdfs/FATF-40-Rec2012-Spanish.pdf
} 
o indirecta. Cuando no sea posible identificar a una persona humana deberá identificarse y verificarse la identidad del Presidente o la máxima autoridad que correspondiere." 22

Sin perjuicio de ello la CNV, ha dictado una serie de normas que obligan a los agentes del mercado de capitales a brindar información, en especial para aquellas constituidas en el extranjero ${ }^{23}$ fijando un umbral más bajo. Dicha norma impone la obligación de informar nombre y domicilio de los accionistas o socios que posean más del 5\% del capital social, detallando si correspondiere, el tipo societario, equivalente funcional y la nacionalidad. Asimismo, se debe presentar: (a) la documentación societaria correspondiente a las personas jurídicas que sean accionistas (contrato constitutivo, estatutos sociales y modificaciones); (b) acompañar nómina de los miembros de órganos de administración y fiscalización; (c) composición del capital social y/o patrimonio indicando la titularidad accionaria final; (d) declaración jurada de no encontrarse sujeta a restricción legal alguna, de poseer capacidad legal para promover acciones judiciales y concluir actos jurídicos y de poseer activos fijos en el lugar de constitución al igual que poseer activos no corrientes en otras sociedades; y (e) los estados contables aprobados de los tres últimos ejercicios.

En relación a dichos requisitos debe especificar: (a) la composición del capital social indicando titularidad accionaria tomando los recaudos suficientes para poder identificar al beneficiario final de las tenencias, extendiendo el deber de información respecto de patrimonios administrados por terceros. En todos los casos la información debe ser suficiente para poder identificar a todas las partes que integran ese negocio jurídico; y (b) informar el lugar de constitución de la sociedad tenedora de las acciones, especificando que no se encuentra sujeta a restricción o prohibición legal en el país de constitución para realizar actividades comerciales, debiéndose transcribir la normativa societaria y relativa al mercado de capitales que le sea aplicable.

Es decir que para las sociedades extranjeras pareciera ser que establece un umbral para la identificación de beneficiarios final del 5\% en lugar del $20 \%$ al que refiere la UIF. Sin embargo, en el año 2017 se dictó una nueva resolución ${ }^{24}$ que modificó algunos criterios de las normas de la CNV estableciendo la obligación a los accionistas personas jurídicas y otras estructuras jurídicas de informar en detalle sus "Beneficiarios Finales" en las asambleas en las que participe. Está norma no establece umbral y tampoco aclara si se dejan sin efecto normas anteriores.

A lo largo del texto de las Normas de la CNV, reglamentarias de la Ley de Mercado de Capitales, se puede advertir una constante confusión entre accionistas, control directo e indirecto y beneficiario final. Se requiere mucha información sobre los accionistas a partir de un umbral y sobre ese accionista en caso de tratarse de una persona jurídica solicita la identificación de quien ejerza el control.

Del mismo modo se van modificando los umbrales, del 20\%, el 5\%, el $2 \%$ o ninguno. Por ejemplo, dentro del Capítulo XI dedicado a la Prevención del Lavado de Activos, en el apartado sobre requisitos de idoneidad, integridad y solvencia hace mención a los supuestos de que se trate de personas jurídicas u otros entes asimilables, “...la evaluación se hará respecto de cada una de las

\footnotetext{
${ }^{22}$ La última Resolución de la UIF para la CNV fue la n ${ }^{\circ} 21 / 2018$ del 1.03.2018, su antecedente es la Resolución UIF 229/2011 del 13.12.2012 la que definía al "Propietario / Beneficiario: a las personas físicas que tengan como mínimo el VEINTE (20\%) por ciento del capital o de los derechos de voto de una persona jurídica o que por otros medios ejerzan el control final, directo o indirecto sobre una persona jurídica".

${ }^{23}$ Resolución CNV n 604/2012 del 12.04.2012.

24 "BENEFICIARIO FINAL. DEBER DE INFORMAR. ARTÍCULO 24.- Los accionistas, sean estos personas jurídicas u otras estructuras jurídicas, deberán informar a la sociedad sus beneficiarios finales. Las sociedades deberán remitir vía AUTOPISTA DE LA INFORMACIÓN FINANCIERA, como "información restringida a la CNV" bajo el título "Beneficiarios Finales", la información sobre el/los beneficiario/s final/es. A tal fin, deberá constar el nombre y apellido, nacionalidad, domicilio real, fecha de nacimiento, documento nacional de identidad o pasaporte, CUIT, CUIL u otra forma de identificación tributaria y profesión. La información del beneficiario final se deberá remitir en la forma dispuesta dentro de los CINCO (5) días hábiles de celebrada la asamblea.” Resolución CNV n 687/2017
} 
personas físicas que se desempeñen como administradores, directores, gerentes y todos aquellos que desempeñen funciones directivas dentro de la entidad, como así también respecto de sus beneficiarios finales y de las personas humanas o jurídicas que tengan como mínimo el $20 \%$ del capital o de los derechos de voto de la entidad, o que por otros medios ejerzan el control final, directo o indirecto sobre la misma..."

Y continúa diciendo que "...Cualquier designación de administradores, directores, gerentes o personas con funciones directivas, que la entidad efectúe con posterioridad a la autorización, deberá ser notificada a la Comisión para que lleve a cabo la referida evaluación. De igual forma deberá notificarse respecto de los beneficiarios finales y las personas físicas o jurídicas que adquieran como mínimo el $20 \%$ del capital o de los derechos de voto de la entidad, o que por otros medios pasen a ejercer el control final, directo o indirecto sobre la misma."

En esta última parte el beneficiario final y personas que posea el $20 \%$ del capital o derecho de voto, parecieran ser personas diferentes.

Lo mismo ocurre cuando indica que la Comisión no autorizará la oferta pública de valores en los supuestos en que una entidad emisora, sus beneficiarios finales, y las personas físicas o jurídicas que tengan como mínimo el $20 \%$ de su capital o de los derechos a voto, o que por otros medios ejerzan el control final, directo o indirecto sobre la misma, registren condenas por delitos de lavado de activos y/o financiamiento del terrorismo y/o figuren en las listas de terroristas y organizaciones terroristas emitidas por el Consejo de Seguridad de las Naciones Unidas.

Otro ejemplo de la poca claridad se advierte frente al deber informativo de participaciones accionarias. Las personas físicas o jurídicas que en forma directa, por intermedio de otras personas físicas o jurídicas, o cualquier grupo de personas actuando en forma concertada, que por cualquier medio y con una determinada intención:

a) Adquieran o enajenen acciones y/o valores representativos de deuda convertibles en acciones de una emisora, o adquieran opciones de compra o de venta sobre aquellos; b) Alteren la configuración o integración de su participación directa o indirecta en el capital de una emisora; c) Conviertan obligaciones negociables en acciones; d) Ejerzan las opciones de compra o de venta de los valores negociables referidos en el inciso a), o; e) Cambien la intención respecto de su participación accionaria en la emisora, al tiempo de verificarse alguno de los supuestos indicados en los incisos anteriores.

En todos los casos, siempre que las adquisiciones involucradas y/o los hechos referidos precedentemente otorgasen $5 \%$ o más de los votos que puedan emitirse a los fines de la formación de la voluntad social en las asambleas de accionistas, inmediatamente de haberse concertado la adquisición, la enajenación, la alteración de la configuración o integración de su participación, la conversión en acciones, y/o el ejercicio de las opciones o de producido el cambio de intención, deberán informar esa circunstancia a la CNV.

Similar información deberá ser suministrada en cada oportunidad en que se produzcan cambios sobre la tenencia informada, hasta el momento en que por alcanzar la condición de accionista controlante, quede sujeto al régimen previsto para éstos. La información respectiva deberá remitirse en los formularios disponibles en la autopista de la información financiera a través de la página web del organismo Esta información deberá contener los siguientes datos:

“1) Datos de las personas físicas o jurídicas que directa o indirectamente integran la participación accionaria mencionada...5) Fecha de alteración de la configuración o integración de su participación directa o indirecta.6) Intención -según corresponda original o nueva- de las personas físicas o jurídicas que directa o indirectamente integran la participación accionaria mencionada, respecto de la misma (por ejemplo: adquirir una participación mayor, alcanzar el control de la voluntad social de la emisora, enajenar parcial o totalmente la tenencia y/o todo otro propósito). 
Las personas físicas o jurídicas que directa o indirectamente integran la participación accionaria mencionada deberán, asimismo, remitir la información exigida por el presente artículo a los Mercados en los que se encuentren listados los valores negociables..." 25

Se advierte que de la articulación de las normas citadas no resultan claros los conceptos y requerimientos sobre la solicitud de información del beneficiario final. Cabe agregar que el registro que lleva la $\mathrm{CNV}$ es de carácter confidencial por lo que resulta muy complejo acceder a la información que lleva en sus registros.

\subsection{Superintendencia de Seguros de la Nación (SSN)}

La SSN es un organismo público descentralizado en la órbita del Ministerio de Hacienda, cuya función es la de supervisar de manera integral la actividad aseguradora, reaseguradora y de intermediación en todo el país, y que tiene como principal objetivo promover una plaza solvente, estable y eficiente en beneficio de los asegurados, asegurables, beneficiarios y damnificados. Fundamentalmente protege los derechos de los asegurados mediante la supervisión y regulación del mercado asegurador para un desarrollo sólido con esquemas de controles transparentes y eficaces. Por lo que siendo que los productos y las transacciones de las aseguradoras ofrecen la oportunidad de blanquear capitales o financiar el terrorismo se han adoptado diversas medidas a los fines de su prevención. Entre las ellas, en el año 2018, el organismo puso en marcha el primer sistema informático denominado "beneficiario final" que tiene como objetivo identificar a:

(i) los accionistas personas físicas y personas jurídicas —incluyendo sus accionistas — de las entidades aseguradoras o reaseguradoras locales;

(ii)los componentes de los grupos o conglomerados económicos; y

(iii) los beneficiarios finales.

La Resolución 816/2018 de la SSN provee definiciones y pautas interpretativas de los conceptos de "beneficiario final" y "grupo o conglomerado económico". Refiere al Beneficiario final tal como lo dispone la reformada Ley 25.246, como "...toda persona humana que controla o puede controlar, directa o indirectamente, una persona jurídica o estructura legal sin personería jurídica, y/o que posee, al menos, $20 \%$ del capital o de los derechos de voto, o que por otros medios ejerce su control final, de forma directa o indirecta. Cuando no sea posible identificar a una persona humana deberá identificarse y verificarse la identidad del presidente o la máxima autoridad que correspondiere."

Asimismo incorporó una pequeña norma para interpretar el concepto. Se trata de un agregado positivo para facilitar la real identificación, es novedoso ya que no lo han hecho los restantes organismos en sus normativas internas. Clarifica y efectiviza la correcta identificación. La conceptualización de beneficiario final alcanza a la/s Persona/s que ejerza/n una influencia dominante como consecuencia de la tenencia de acciones, o cuota-partes, poseídas a título personal o por interpósita persona (con la salvedad de que se trate de socio aparente o presta nombre, y socio oculto), o por especiales vínculos existentes entre las personas humanas o jurídicas involucradas; o ejerza/n una influencia dominante generada por una subordinación técnica, económica o administrativa.

Las empresas aseguradoras deben remitir toda la información relacionada al beneficiario final a través de un sitio web, lo que garantiza que el registro se lleve de manera completamente digital. Los datos deben enviarse una vez al año en las fechas estipuladas por la SSN y la información suministrada revestirá carácter de Declaración Jurada. Sin perjuicio de lo anterior, dentro de los cinco días de efectuada la carga de datos, las entidades deben remitir la Declaración

${ }^{25}$ Art. 12 y ss. del Título XII de las Normas de la CNV Res. 622 T.O.2013.

Revista de Direito Brasileira | Florianópolis, SC | v. 24 | n. 9 | p.222-249 | Set./Dez. 2019 
Jurada a través de la plataforma informática de Trámites a Distancia (TAD). La puesta en marcha de este nuevo sistema informático no exime a las entidades del cumplimiento de los procedimientos o trámites que exigen la presentación en soporte físico o digital de la misma información.

Cabe destacar que la inobservancia de las pautas previstas en relación a la presentación de la información del beneficiario final importará un ejercicio anormal de la actividad aseguradora, por lo que será pasible de recibir sanciones, tales como apercibimiento, multas y hasta la suspensión de la actividad. ${ }^{26}$

\section{LAS SOCIEDADES EXTRANJERAS}

Las sociedades extranjeras constituyen uno de los principales vehículos jurídicos utilizados para ocultar a los verdaderos dueños de los negocios. Antes de avanzar es necesario realizar una distinción entre las sociedades extranjeras y las sociedades offshore. Las primeras son aquellas que están constituidas en el extranjero, se rigen en cuanto a su existencia y forma por las leyes del lugar de origen y es posible distinguir cuatro supuestos para actuar en Argentina: a) sociedades extranjeras que realicen actos aislados como puede ser la compra de un inmueble; b) empresas que ejecuten actos comprendidos en su objeto social, por ejemplo, el establecimiento de una sucursal o representación permanente; c) sociedades extranjeras que participan en otras sociedades mediante la compra de un paquete accionario o la participación en su calidad de accionista desde su origen en una sociedad local; y, d) sociedades extranjeras que tengan su sede principal y cumplan su objeto social en la Argentina, para lo que deberá adecuarse a la normativa nacional. La información de ellas se encuentra en sus registros públicos de origen y en el registro público de la jurisdicción nacional de que se trate. En tanto, las sociedades offshore, son aquellas constituidas en jurisdicciones cuyo principal atractivo son los beneficios que otorgan a quienes desean constituir allí una sociedad: bajos o nulos impuestos, confidencialidad de la información, trabas al momento de tener que intercambiar información, regulaciones laxas para la constitución de la sociedad, estabilidad política, desregulación financiera y cambiaria, extraterritorialidad para el cumplimiento del objeto social. Estas jurisdicciones suelen contar con una desarrollada industria de servicios financieros que, como evidencian las megafiltraciones como Panama Papers o Paradise Papers, facilitan la evasión, el lavado y otras actividades ilícitas.

Estas últimas estructuras son las más utilizadas para delinquir, para introducir el dinero habido de negocios espurios al circuito comercial legal, o bien para ocultar la identidad de los reales dueños del negocio que intentan a toda costa esconderse de las autoridades de su país.

Entre 2003 y 2015, Argentina experimentó un incremento en los controles sobre este tipo de personas jurídicas, específicamente a través de la Inspección General de justicia que dictó una serie de normas. La normativa desplegada entre 2003 y 2005 obligaba a las sociedades extranjeras que llegaban a nuestro país a presentar una serie de documentos con información precisa sobre la composición de su patrimonio, datos completos de sus socios, estados contables, designación de representantes legales, legajos de las casa matrices, entre otras. Parte de dicha información también debía actualizarse a través de la presentación del régimen informativo anual previsto solamente para las sociedades extranjeras. Asimismo prohibió la inscripción de las sociedades offshore como así también quedó vedada toda actividad que pretendiera ejercer este tipo de sociedad en la jurisdicción de la Ciudad de Buenos Aires. Se creó también un registro de actos aislados donde se inscribían las operaciones que realizaban por única vez y fuera de su objeto principal las sociedades extranjeras (como, por ejemplo, la compra de inmuebles en nuestro país).

A pesar de los esfuerzos para contar con información completa de las sociedades extranjeras, el andamiaje construido comenzó a desmontarse en 2018. Con el propósito (o excusa) de dar cumplimiento con lo establecido en un decreto del Poder Ejecutivo Nacional respecto de las

${ }^{26}$ Véase art. 58 Ley 20.091.

Revista de Direito Brasileira | Florianópolis, SC | v. 24 | n. 9 | p.222-249 | Set./Dez. 2019 
"buenas prácticas en materia de simplificación” de trámites y procesos para la Administración Pública Nacional $^{27}$ y siguiendo con la misma premisa de la Ley ${ }^{\circ} 27.444$ que establece como prioridad dinamizar el funcionamiento, financiamiento y productividad de las sociedades comerciales, brindando -supuestamente- un mejor acceso a los servicios que presta el Estado, la Inspección General de Justicia (IGJ) dictó la Resolución General 6/2018. A través de dicha resolución, la IGJ flexibilizó los requisitos de inscripción y regímenes informativos que las sociedades extranjeras deben cumplir para poder establecer una sucursal en la Argentina y/o participar como socia de una sociedad constituida en el país, tirando por tierra la construcción normativa seguida por la jurisprudencia administrativa y judicial hasta la fecha ${ }^{28}$. A continuación, se describen las principales modificaciones.

1) Respecto de la Inscripción inicial: Se eliminó el requerimiento de acreditación de actividad principal fuera del país y de individualización de los socios cuando se solicita la inscripción inicial de sociedades extranjeras ${ }^{29}$. La norma anterior requería que las sociedades extranjeras acrediten (i) el desarrollo en el exterior de actividad empresarial económicamente significativa y (ii) que el centro de dirección de dicha actividad también se localizaba en el exterior.

2) Información de los socios: Se eliminó la obligación de informar e individualizar la nómina de socios de la sociedad extranjera, de brindar información sobre los mismos, aunque continúa vigente la obligación de presentar una declaración jurada informando quiénes son sus beneficiarios finales, en los términos del art. 518 Resolución General (RG) 07/15. En tal sentido, deberán continuar con la generación anual de la Declaración Jurada, pero deberán presentarlas en IGJ en la primera oportunidad en que se solicite la inscripción de algún trámite registral, no imponiéndose la obligación de la presentación anual. Es sabido que esta información no es suministrada por las compañías de manera adecuada, ni se cuenta con un registro efectivo y veraz sus beneficiarios finales. Ello por cuanto la declaración jurada brinda la posibilidad de indicar que la sociedad no posee beneficiarios finales, la que suele utilizarse cuando existe una cadena de titulares personas jurídicas.

3) Régimen informativo anual: Se eliminó la obligación de efectuar esta presentación tanto para sociedades extranjeras inscriptas en los términos del art. 118 (inscripción de una sucursal) como en los del art 123 (inscripción para participar como socia en una sociedad local) de la Ley General de Sociedad (LGS), manteniéndose para las primeras únicamente la obligación de presentar anualmente los estados contables de la sucursal, asiento o representación permanente. Mediante el régimen informativo anual, las sociedades extranjeras debían anualmente revalidar su inscripción cumpliendo con la presentación de información relacionada a sus socios y activos.

4) Representación: Se eliminó la restricción de la normativa previa que establecía que las sociedades extranjeras únicamente podían actuar en los actos sujetos a inscripción exclusivamente por intermedio de su representante inscripto o apoderado investido por este. Conforme el nuevo texto, pueden representar a las sociedades extranjeras tanto el representante inscripto como un apoderado designado por la casa matriz.

5) Actos aislados: Se derogó todo el capítulo vinculado con actos aislados, y todo registro que se llevaba de ellos. Este capítulo permitía a la IGJ receptar información proveniente de registros de bienes y/o derechos relacionados a la celebración de actos en los cuales hayan participado sociedades constituidas en el extranjero y cuyo objeto haya sido la constitución,

\footnotetext{
${ }^{27}$ Decreto P.E.N. n ${ }^{\circ} 891 / 2017$

${ }^{28}$ La Resolución General 6/2018 sustituye varios artículos de la Resolución General 07/15 de la IGJ, y deroga muchos otros, todos ellos vinculados a las sociedades extranjeras.

${ }^{29}$ Sociedades extranjeras en los términos del artículo 118 y 123 de la Ley General de Sociedades Revista de Direito Brasileira | Florianópolis, SC | v. 24 | n. 9 | p.222-249 | Set./Dez. 2019
} 
adquisición, transmisión o cancelación de derechos reales y hayan sido calificados unilateral o convencionalmente como realizados en carácter de actos aislados. Con dicha información se iniciaba un procedimiento de investigación, que podía culminar con la intimación a la sociedad a su inscripción en los términos del art. 118 o 124 de la LGS. Dicho registro intentaba evitar el abuso del acto aislado.

6) Cancelación por inactividad de sucursales: Se eliminó el requisito que establecía que, para poder cancelar por inactividad, las sucursales debían tener una vigencia no mayor de cinco años. Es decir que ahora cualquier sucursal que acredite inactividad y cumpla con los requerimientos de la norma puede solicitar la cancelación registral por inactividad.

7) Sociedad con domicilio o principal objeto en la República: Se eliminaron los elementos de ponderación para establecer si una sociedad extranjera encuadra en el artículo 124 de la LGS. Mantienen el procedimiento para llevar adelante la nacionalización.

8) Respecto de la inscripción de sociedades vehículos: Aquellas sociedades entendidas como instrumento de inversión de otra sociedad extranjera que directa o indirectamente ejerza su control por poseer derechos de voto suficientes para formar la voluntad social de la peticionaria experimentaron la eliminación de todos los requisitos particulares que se exigían de este tipo de sociedades. Las mismas deberán cumplir únicamente con los requisitos generales.

9) Sociedades offshore: La norma anterior disponía que las sociedades offshore eran aquellas que, conforme a las leyes del lugar de su constitución, incorporación o registro, tenían vedado o restringido en el ámbito de aplicación de dicha legislación, el desarrollo de todas sus actividades o la principal de ellas. Tales sociedades, tenían prohibida la inscripción en IGJ como sociedades extranjeras, y para desarrollar actividades destinadas al cumplimiento de su objeto y/o para constituir o tomar participación en otras sociedades, debían con carácter previo adecuarse íntegramente a la legislación argentina, cumpliendo el procedimiento previsto en la RG 07/15. Dicha prohibición fue eliminada.

10) Se introdujo la posibilidad de que la IGJ analice la inscripción de sociedades provenientes de países con regímenes tributarios especiales o considerados no cooperadores en materia de transparencia fiscal, mediante el requerimiento de documentación que acredite actividad económicamente significativa en el exterior. La IGJ se reservó, la facultad de solicitar documentación de activos, así como también de individualizar los socios de sociedades provenientes de países, dominios, jurisdicciones, territorios, estados asociados y regímenes tributarios especiales considerados no cooperadores a los fines de la transparencia fiscal o no colaboradores en la lucha contra el lavado de activos y financiación del terrorismo.

Esta nueva resolución dió un vuelco de ciento ochenta grados en materia de control societario sobre las sociedades extranjeras en el ámbito de la Ciudad de Buenos Aires. Ahora bien, lejos de considerar que el espíritu principal de esta nueva norma se encuentra centrado en la desburocratización del Estado, simplificación de trámites, es evidente que se trata de la apertura de una puerta para el ingreso de capitales extranjeros sin importar su procedencia. Asimismo, es evidente que en cada una de las modificaciones introducidas se restringe el acceso a la información sobre los verdaderos dueños.

En lo referido a las sociedades offshore, como se mencionó anteriormente dentro de sus principales características se encuentran el anonimato -lo que impide conocer a su verdaderos dueños o beneficiarios-, el secreto en las transacciones, la fácil y ágil constitución, los mínimos requisitos a acreditar, la no registración en libros societarios, etc. Su finalidad es actuar fuera de las fronteras del lugar de su constitución, teniendo vedado o sumamente limitado el desarrollo de su objeto social en el país que les otorga el reconocimiento de la personalidad jurídica. Están destinadas a una actuación exclusivamente extraterritorial. Es decir, resulta casi imposible recabar información sobre este tipo societario. Uno de los principales perjuicios los sufrirá la Unidad de 
Información Financiera ante el casi nulo control y falta de información que se tendrá sobre este tipo de personas jurídicas.

Será un obstáculo también para las investigaciones que lleva adelante el Poder Judicial en el marco de aquellas que requieren seguir el camino de dinero habido del delito, entre otros. La Inspección General de justicia es el principal Registro Público de personas jurídicas de nuestro país, por lo que el mayor caudal de sociedades tiene su domicilio y centro principal de administración en la Ciudad de Buenos Aires. Esta norma abre una puerta por demás problemática. Sin perjuicio de ello, en las restantes Direcciones de Personas Jurídicas de nuestro país, siempre fue posible que las sociedades offshore se inscriban.

Sin dudas, se relajaron los controles a las sociedades offshore. No es una adecuada política regulatoria permitir la actuación de sociedades off shore o disminuir los controles administrativos sobre ellas, en tanto ello no se reproducirá en más inversiones extranjeras. Es un grave error pensar que flexibilizar controles sobre las sociedades extranjeras impactará de manera positiva en el mercado local por el arribo de inversiones del exterior. Aquellas sociedades extranjeras que nada tengan que ocultar entonces serán bienvenidas y cumplirán sin inconvenientes con los requisitos que les exige la ley.

Asimismo pareciera que terminarían teniendo hasta un trato preferencial frente a las sociedades propiamente argentinas, a las que se les exige el cumplimiento de mucho requisitos legales para formalizar su operatoria comercial.

La vigencia actual de la norma modificada no solamente expone al país a la vulnerabilidad de ser utilizado para lavar y esconder activos provenientes del delito, sino que impide brindar cooperación internacional eficaz a otros; es decir que expone también a otros países. Seguidamente al dictado de esta norma y en el marco del mismo decreto presidencial orientado a la desburocratización, modernización y simplificación de trámites e insistiendo en la necesidad de implementar regulaciones de cumplimiento simple que mitiguen la carga burocrática para la realización de actividades tanto en el ámbito de la Administración Pública como en el sector privado es que a través de la Ley de Financiamiento Productivo (LFP) ${ }^{30}$ se introdujeron modificaciones a la regulación del Mercado de Capitales.

Más específicamente, la LFP en su Título III, artículo 64 introdujo en la Ley de Mercado de Capitales $\mathrm{N}^{\circ} 26.831$ (LMC), el artículo 62 bis $^{31}$, con el objetivo de habilitar la participación de las personas jurídicas extranjeras en las asambleas de sociedades por acciones a través de mandatarios debidamente instituidos, sin otra exigencia registral.

Fundan tal incorporación en los Principios de Gobierno Corporativo de la Organización para la Cooperación y el Desarrollo Económico (O.C.D.E) en especial en el enfocado en "proteger y facilitar el ejercicio de los derechos de los accionistas y garantizar el trato equitativo entre ellos, incluidos los minoritarios y extranjeros". Y agregan que también recomienda que los inversores extranjeros tengan las mismas oportunidades que los nacionales para ejercer sus facultades como propietarios.

Siguiendo estos lineamientos y fundamentos, a efectos de reglamentar esta normativa, la Comisión Nacional de Valores dictó la Resolución n 789/2019 mediante la cual sustituyó lo dispuesto en el artículo 25 del Capítulo II del Título II de las Normas Generales de la CNV (N.T. 2013 y mod.), por el siguiente texto: “Artículo 25.- En el caso de una persona jurídica constituida

\footnotetext{
${ }^{30}$ Ley n$^{\circ}$ 27440. De Financiamiento Productivo del 9.05.2018

${ }^{31}$ Art. 62 bis. LMC ap. "II. Las personas jurídicas constituidas en el extranjero podrán participar de todas las asambleas de accionistas, incluyendo -aunque sin limitación- las contempladas en el presente artículo, de sociedades autorizadas a hacer oferta pública de sus acciones a través de mandatarios debidamente instituidos, sin otra exigencia registral."
} 
en el extranjero, para poder participar en una asamblea de accionistas, será suficiente la presencia de mandatario debidamente instituido, sin otra exigencia registral.

En este contexto, cabe destacar que la normativa anterior de la CNV - del año 2017preveía justamente lo contrario. En efecto, exigía un control más exhaustivo y se fundaba también en los principios de transparencia del Grupo de Acción Financiera Internacional (G.A.F.I). En particular, establecía que para que una persona jurídica constituida en el extranjero pueda participar de una asamblea debía acreditar el instrumento en el que conste su inscripción en los términos de los artículos 118 o 123 de la LGS, cuya previsión obliga a las sociedades extranjeras a inscribirse en el registro público en caso de desarrollar su objeto principal en el Argentina o bien constituir y/o adquirir participaciones en una sociedad nacional.

Esta última medida resulta coherente con sus antecedentes, dado que la Resolución 604/12 de la CNV contemplaba una serie de exigencias a emisoras constituidas en el extranjero, con fundamento en los principios de "transparencia", "información plena", "protección del público inversor", "trato igualitario entre inversores", etc. siguiendo recomendaciones internacionales en la materia.

En ese mismo sentido se ha desenvuelto la actividad de la CNV en los últimos años pues ha bregado y fundado sus normas en principios de organismos internacionales tendientes a transparentar y recabar información en pos de impedir el uso indebido de las personas jurídicas.

Sin embargo, mientras la CNV dictaba normas tendientes a ejercer un mayor control a la par de contar con más información cuando se trataba de empresas y/o capitales provenientes del extranjero -en particular las citadas Resoluciones de los años 2012 y 2017-, lo cierto es que en las nuevas decisiones adoptadas por la Comisión se advierte un giro radical dado que no hacen más que opacar su personalidad jurídica o casi volverlas invisibles a los ojos de nuestro Estado Nacional, en abierta contradicción con los antecedentes normativos tendientes a transparentarlas.

En otras palabras, a las sociedades extranjeras que participen como accionistas en asambleas de sociedades nacionales no se les exigirá estar inscriptas en el Registro Público que corresponda. Ello significa que no existirá información de las mismas y por ende tampoco de sus beneficiarios finales.

En este punto, se observa un retroceso en materia de transparencia. Tales políticas de manera alguna podrán atraer a capitales extranjeros en tanto a atenta contra el orden internacionales que brega por sistemas ágiles - por supuesto- pero de registro, control y recabamiento de información.

Esta norma se suma a las tantas otras que convierte a la Argentina en un destino tentador para las organizaciones criminales que buscan deseosas países con normas laxas y de fácil acceso, sin cruce de datos ni controles de algún tipo. Garantizar la laxitud en materia de participación de sociedades extranjeras y eliminar controles sobre las mismas en actos asamblearios de empresas nacionales que se encuentren bajo la órbita de competencia de la Comisión Nacional de Valores, resulta por demás peligroso para el ingreso de capitales de origen delictivo.

\section{EL REGISTRO NACIONAL DE SOCIEDADES}

Un registro nacional de sociedades constituye un instrumento necesario e imprescindible para favorecer el desenvolvimiento de las personas jurídicas, colabora en la implementación de políticas sobre transparencia en el tráfico mercantil y aporta al desarrollo de las actividades que estas realizan en las distintas jurisdicciones. Una herramienta de esas características permite a un país contar con datos e información básica que sirve para desarrollar políticas públicas sobre las áreas, temas, actividades y demás datos que resultan de archivos centralizados con alcance nacional.

Contar con un registro completo, actualizado y público permite también que terceras partes, entre los que se encuentran fundamentalmente los operadores de justicia y quienes desean 
iniciar un negocio jurídico o quienes contraten con personas jurídicas ya inscriptas, puedan efectuar consultas. Esto abre una nueva dimensión al derecho de acceso a la información pública, compatibles con las exigencias de publicidad y transparencia.

En esta sintonía y luego de muchos años de espera, de proyectos inconclusos y de reclamos por parte de diversos sectores de la sociedad y de organismos internacionales, en mayo de 2019 se lanzó el nuevo Registro Nacional de Sociedades bajo la órbita del Ministerio de Justicia y Derechos Humanos.

La función principal del registro es la de administrar y centralizar en una única base de datos información de sociedades accionarias y no accionarias nacionales, de sociedades extranjeras, de asociaciones civiles y de fundaciones, de todo nuestro país.

A través de una plataforma en línea de acceso público y gratuito se podrá consultar cierta información de personas jurídicas provista por la Administración Federal de Ingresos Públicos (AFIP), previa verificación con los datos provistos por los distintos registros públicos, en su caso.

De dicha base de consulta pública se podrá obtener el domicilio social registrado por cada persona jurídica, a partir del cual se podrá inferir la jurisdicción local de registro de la persona jurídica consultada. Se Informará también sobre los siguientes datos de las personas jurídicas: 1) Denominación social; 2) Tipo social; 3) Fecha de contrato social ; 4) Número de registro local (cuando está disponible); 5) Domicilio fiscal; 6) Domicilio legal.

Partiendo del dato del domicilio legal, los consultantes podrán obtener la jurisdicción del registro provincial o de la Ciudad de Buenos Aires y allí dirigirse para requerir la documentación, información y antecedentes de la persona jurídica objeto de consulta.

Ahora bien, toda la información que se recabe dependerá de los compromisos que asuman los Registros Públicos de cada jurisdicción y siempre que cuenten con la tecnología para lograr remitir la información de la manera digital.

Tal como se analizó en el apartado 3.2, cada provincia tiene sus propias normas y procedimiento lo que genera que no se soliciten los mismo datos, ni del mismo modo en todas las jurisdicciones. Ello entorpece muchas veces la propia función del Registro nacional. Y específicamente es lo que ocurre en materia de beneficiario final en tanto sólo 3 de los 36 registros de todo el paìs recaban información de los mismos.

Es importante destacar que los datos que requieren los registros nacionales como información a brindar desde los registros jurisdiccionales locales, son datos registrales públicos respecto de personas jurídicas y de aquellas que las componen, sean jurídicas o humanas.

No se trata de datos sensibles, sino que la propia Ley $\mathrm{n}^{\mathrm{o}} 26047$, reglamentaria de los Registros Nacionales, establece cuáles son los datos necesarios y de interés que constituyen la información que debe centralizarse a los fines de generar mayor y mejor publicidad y transparencia. La mencionada norma fue modificada por la hace poco menos de dos años y expresamente prevé que "las dependencias administrativas y autoridades judiciales de las distintas jurisdicciones que, conforme a la legislación local, tengan asignadas las funciones del registro público para la inscripción de la constitución y modificación de sociedades locales y extranjeras y las funciones para autorizar la actuación como personas jurídicas de carácter privado de las asociaciones civiles y fundaciones locales y extranjeras, remitirán por medios informáticos al Ministerio de Justicia y Derechos Humanos o al organismo que éste indique al efecto, los datos que correspondan a entidades que inscriban. modifiquen o autoricen a partir de la fecha que determine la reglamentación."

Y agrega que "se incluirán entre las modificaciones las que indiquen cambios en la integración de los órganos de administración, representación y fiscalización de las personas jurídicas; las transmisiones de participaciones sociales sujetas a inscripción en el registro público; el acto de presentación de estados contables; los procedimientos de reorganización, disolución y 
liquidación de sociedades y entidades y las declaraciones juradas de beneficiarios finales de las mismas." 32

Ello significa que el registro público de beneficiarios finales se encuentra en cabeza del Registro Nacional de Sociedades.

Resulta de suma importancia que un registro único pueda conocer a los verdaderos dueños de las personas jurídicas inscriptas en los Registros Públicos. Sin perjuicio de ello, a nivel internacional aún se mantienen debates en torno a la información que debería ser publicada y la que no. La Argentina no ha sido ajena a dicha discusión y ello también ha sido motivo de retrasos. Temores como la seguridad física y patrimonial de los sujetos son son algunos de los temas que se cuestionan, considero que los mismos son perfectamente subsanable a través de otras medidas de protección de la información por lo que no debería ser una excusa para seguir dilatando la concreción de un RNS completo y un registro público de beneficiarios finales.

El nuevo registro todavía no reúne ni brinda información sobre la constitución y su modificaciones serán, por ejemplo, cambios en la integración de los órganos de administración, representación y fiscalización de las personas jurídicas, transmisión de participaciones sociales, el acto de presentación de estados contables, procedimientos de reorganización, disolución y liquidación, etc. En efecto, el Poder Judicial, el Ministerio Público, los organismos de la Administración Pública Nacional, como ser la Unidad de Información Financiera o la Oficina Anticorrupción, los profesionales del derecho, entre otros, hace años reclaman la puesta en marcha real y eficaz de los Registros Nacionales, como fuente de consulta certera y ágil en medio de investigaciones que requieren rápidas respuestas para poder avanzar y culminar.

Un registro completo y ágil permitiría, por ejemplo, en una sola consulta identificar en cuantas sociedades a los largo y ancho del país participa una persona humana ya sea como administrador o como beneficiario final.

Habida cuenta que las organizaciones criminales operan a través de personas jurídicas nacionales y/o preferentemente extranjeras, contar con información de todas las jurisdicciones, lograr cruzarla y procesarla sería un avance importantísimo en la materia.

Unificar criterios, procesos de solicitud de información, brindar herramientas tecnológicas a todas las jurisdicciones tal como lo prevé la ley 26.047, serian los pasos a seguir.

En tanto no exista información respecto de los integrantes de las personas jurídicas, su administradores, capital y mucho menos de los beneficiarios finales, continuaremos en deuda con nuestro sistema de justicia.

De todas maneras y siendo que se trata de un Registro que viene haciendo un gran esfuerzo por salir a la luz hace muchos años, su implementación es un avance.

Hoy brinda algunos datos que permiten rastrear donde tiene su asiento principal una sociedad, lo que facilita - al menos- saber a dónde ir a buscar más información o bien efectuar controles de homonimia a nivel nacional.

Este nuevo Registro Nacional resulta ser un paso en materia de gobierno y datos abiertos y acceso a la información. Los sistemas de datos abiertos, cuando se implementan correctamente, permiten el desarrollo de múltiples herramientas y sistemas que resultan de mucha utilidad para muchos sectores de la sociedad. En tanto, tales registros podrían vincularse con otros conjuntos de datos de interés público.

\section{LOS BENEFICIARIOS FINALES Y LOS TESTAFERROS}

Una figura muy utilizada para ocultar a los verdaderos dueños ha sido la del testaferro (existen diversas formas conocidas como "socio oculto", "socio aparente", "socio del socio" 33

\footnotetext{
${ }^{32}$ Véase art.26 Ley 27.444, reforma y sustituye el artículo 4 del la Ley 26.047.

${ }^{33}$ Los textos anteriores de la ley 19.550 decían:
}

Revista de Direito Brasileira | Florianópolis, SC | v. 24 | n. 9 | p.222-249 | Set./Dez. 2019 
dentro de las estructuras jurídicas). Todas estas formas de ocultamiento se encontraban legitimadas en el ordenamiento jurídico argentino y han sido históricamente utilizadas como herramientas para la comisión y/o el ocultamiento de patrimonios de origen lícito o ilícito.

Los más utilizados, también suelen ser las personas jurídicas como testaferros, para ocultar propiedades con finalidades de evasión familiar, patrimonial o fiscal. La vigencia de los artículos 34 y 35 de la Ley General de Sociedades (LGS) fue motivo de observaciones por parte del GAFI y de acuerdo a su, por entonces Recomendación 33 correspondiente al Beneficiario Final, recomendó modificarlos en la medida en que no colaboran a la transparencia buscada en la integración de sociedades comerciales. ${ }^{34}$

Por ello y de la mano del decreto del Poder Ejecutivo Nacional 27/2018, se reformó la LGS, en especial las disposiciones relacionadas al uso de la figura del socio oculto, socio aparente y socio del socio. La reforma prohíbe la actuación societaria del socio aparente o presta nombre y la del socio oculto y extiende la responsabilidad en caso de que dicha prohibición sea incumplida. ${ }^{35}$

Específicamente en materia de personas jurídicas, la problemática del socio aparente o prestanombre y del socio oculto remite a la cuestión del testaferro, esto es a la actuación de una persona que, actuando en nombre propio (socio aparente o testaferro) en rigor ejecuta intereses ajenos (socio oculto o principal), es decir, del real dueño de la participación.

Se trata de un sistema de interposición personal en la titularidad de bienes, derechos o funciones, donde el sujeto que aparece como titular no es tal sino que lo hace en interés y sometido a la voluntad de otro sujeto (el principal o titular real).

Existen diversas formas de utilizar la figura del testaferro, como personas humanas pueden mencionarse los siguientes:

Testaferros profesionales. Se trata de personas con título profesional o avezadas en los negocios a las que, en muchos casos, se les promete una participación en los resultados.

Testaferros empleados. Generalmente son ya empleados de confianza del principal o de sus profesionales.

Testaferros homeless. Se trata de una persona desocupada o sub-ocupada, poco instruida, carente de bienes y que se limita a firmar lo que se le solicita a cambio de una retribución fija o de un pago al momento de cada firma.

Testaferros familiares. Es muy frecuente que se utilice al cónyuge o a un pariente sanguíneo o político del principal. Generalmente no se firma un "contradocumento" por la confianza y porque el encargo suele ser gratuito.

En materia de testaferros societarios pueden distinguirse, entre otros, tres casos:

1) Sociedades extranjeras. La sociedad está constituida en el exterior (art. 118 LGS), carece de actividades en el país y aparece como titular de un bien, pero el "principal" no aparece ni como socio ni como administrador de la misma. Es el caso, entre otras, de las sociedades

\footnotetext{
Art. 34 "SOCIO APARENTE: El que prestare su nombre como socio no será reputado como tal respecto de los verdaderos socios, tenga o no parte en las ganancias de la sociedad: pero con relación a terceros, será considerado con las obligaciones y responsabilidades de un socio, salvo su acción contra los socios para ser indemnizado de lo que pagare"."SOCIO OCULTO: La responsabilidad del socio oculto es ilimitada y solidaria en la forma establecida en el art. 125 ".

Art. 35 "SOCIO DEL SOCIO: Cualquier socio puede dar participación a terceros en lo que le corresponde en ese carácter. Los partícipes carecerán de la calidad de socio y de toda acción social; y se les aplicarán las reglas sobre sociedades accidentales y en participación".

${ }^{34}$ Informe de de la tercera ronda de evaluación mutua del GAFI en la Argentina, del 16/12/2010.

${ }^{35}$ ARTÍCULO 34.- Prohibición. Queda prohibida la actuación societaria del socio aparente o presta nombre y la del socio oculto" (art. $3^{\circ}$ Dec.27/2018).

ARTÍCULO 35.- Responsabilidades. La infracción de lo establecido en el artículo anterior, hará al socio aparente o prestanombre y al socio oculto, responsables en forma subsidiaria, solidaria e ilimitada de conformidad con lo establecido por el artículo 125 de esta Ley" (art. $4^{\circ}$ Dec.27/2018).
} 
"off shore", con acciones al portador, y el de otras sociedades extranjeras cuando los socios y administradores son terceras personas jurídicas o humanas.

2) Sociedades locales "no operativas". Es similar al anterior en cuanto la sociedad fue constituída a los fines de la titularidad y no es operativa pero el verdadero dueño figura como socio y administrador

3) Sociedades locales "operativas". La sociedad ejerce su objeto social y no fue constituìda para una titularidad ficta. Sin embargo, hay bienes de terceros o de socios que figuran en su patrimonio, hipótesis frecuente en sociedades de familia

La reforma es un avance en materia de transparencia ya que declara ilícito el acto de constitución de un testaferro societario y la causa del mandato. En consecuencia, a partir de ahora, tanto la adquisición o transferencia de la propiedad de las acciones, cuotas o participaciones sociales por cualquier título (aporte inicial, compraventa, donación, suscripción de aumento de capital, etc.), como el mandato a tales fines, deben reputarse nulos al tener un objeto prohibido por la ley, en la medida en que existan un socio oculto y un socio aparente.

Ello sin duda que tendrá importantes y trascendentes efectos frente a la sociedad, los otros socios y a los terceros, que podrán desconocer el acto e impedir la actuación del testaferro en los actos sociales. Es dable mencionar que la prohibición de testaferro rige sólo para los casos de titularidades societarias.

\section{CONCLUSIONES}

La identificación de los beneficiarios finales de las empresas representa una de las principales herramientas para combatir los flujos financieros ilícitos relacionados con la evasión fiscal, el lavado de dinero, la corrupción y diversas violaciones a los derechos humanos. La creación de registros públicos permite individualizar a los "verdaderos" dueños, personas humanas, que finalmente poseen o controlan a las estructuras jurídicas que operan cuentas bancarias, administran propiedades u ofrecen bienes y servicios. Sin políticas sobre transparencia respecto de los beneficiarios finales, la criminalidad económica puede ocultarse detrás de vehículos jurídicos de cualquier tipo.

No se trata sólo de pedirle a las empresas que identifiquen e informen quiénes son los verdaderos dueños sino que se debe lograr que no mientan al momento de brindar dicha información. Para evitar que ello suceda es fundamental que exista una interconexión entre los todos los datos públicos existentes en el sistema a los fines de garantizar que la información que proporcione sea válida y certera. Por ejemplo: que los datos brindados sobre una persona humana argentina coincidan con los registrados en el Registro Nacional de las Personas, conforme su nombre, apellido y DNI, los mismo para el caso que se encuentre o no fallecida. Que los domicilios informados sean reales, conforme cruce con google maps, entre otros.

Organizar bases de datos que reúnan la información de los diferentes registros y entidades financieras a los fines de identificar operaciones sospechosas que aumenten los niveles de inusualidad respecto de una maniobra de lavado de activos, como ser un mismo beneficiario de muchas empresas, beneficiarios cuyos ingresos no guarden relación con las ganancias declaradas, hoy en día ello no es posible.

Es necesario repensar la función y la importancia de los registros públicos de personas jurídicas y su rol en la economía y en la lucha contra el lavado de flujos financieros ilícitos. Siendo que son los propios registros públicos quienes de alguna manera les dan vida al otorgarle la personalidad jurídica, permitiéndole de este modo adquirir bienes, abrir cuentas, realizar negocios, etc. Su desempeño es vital para el desarrollo de la economía de un país por ello deben dejar de ser considerados como meros almacenes o buzones emisores de plantillas de inscripción. 
Los registros deben ser considerados como bases de datos dinámicas certeras que permitan a los sujetos involucrados en la dinámica empresarial -bancos, escribanos u otros proveedores de servicios- hacer consultas en tiempo real previo a que se efectivicen las operaciones, por ejemplo: la verificación de que una empresa se encuentra activa, su autoridades debidamente inscritas y vigentes y sus beneficiarios reales informados, previo a la compra de un inmueble.

Aún restan restan muchos desafíos a nivel nacional e internacional por cumplir, como así también revalorizar a las instituciones que lejos de ello cada días resultan más disminuidas en algunos países, tal es el caso de la Argentina.

En efecto, si bien Argentina cuenta con normativa y legislación relacionada al Beneficiario Final aún no cuenta con un abanico de herramientas y recursos que le permitan implementar a nivel nacional y provincial efectivamente sus metodologías de identificación. Entre ellas se pueden enumerar:

1) Educativas, para la comprensión completa del tema y la importancia de tener conocimiento del o los real/es beneficiario/s finale/s de la/s empresa/s.

2) Informáticas, que permitan procesar la información y cruzarla entre los diferentes organismos del Estado o autoridades gubernamentales a los fines de contar con registros ágiles y completos que nos permitan obtener la información de manera rápida y eficaz.

3) Legislativas, que permitan unificar los criterios de los distintas jurisdicciones.

4) Operativas que permitan elaborar procesos y criterios uniforme en todo el país.

La falta de un Registro Unificado que permita reunir la información de todas las personas y estructuras jurídicas del país. Conforme se desarrolló a lo largo del presente trabajo son varios los Organismo Nacionales y locales que recaban información sobre los beneficiarios finales pero aún no se ha logrado que dicho información se centralice y resulte de uso efectivo.

Desde un análisis fundado en la criminalidad económica sabemos que las grandes organizaciones operan a través de múltiples capas de personas jurídicas, por ello Organismos Internacionales como el Grupo de Acción Financiera Internacional (G.A.F.I.) y la Organización para la Cooperación y el Desarrollo Económico (O.C.D.E.), entre otros han arbitrado diversas medidas y/o recomendaciones a los fines de disuadir la utilización de sociedades offshore, estructuras jurídicas como pantallas para la comisión de delitos, violar la ley y frustrar derechos de terceros.

Para que un Estado pueda trazar un camino de crecimiento y una adecuada inserción internacional es imprescindible que cuente en su ordenamiento jurídico con normas claras y coherentes, sistemáticamente armonizadas. Es fundamental un régimen jurídico preciso, que recepte los estándares internacionales y que muestre al país ante un Estado confiable y dotado de seguridad jurídica.

Sin embargo, a lo largo del desarrollo y análisis de la normativa y la práctica existente en nuestro país se advierte un doble juego. Vasta normativa, con definiciones y trámites burocráticos que lejos de armar un claro registro, dejan mucho que desear.

Ello por cuanto, mientras por un lado se busca la identificación del real Beneficiario Final por otro lado se dictan normas a nivel nacional y resoluciones locales que tienden a evitar su correcta identificación.

Claro ejemplo se advirtió en materia de sociedades extranjeras, principales vehículos utilizado para la fuga de capitales, la evasión de impuesto y el lavado de activos, en la Comisión nacional de valores, en la ausencia de normas en 33 de los 36 registros de control y fiscalización de personas jurídicas de nuestro país.

No contar con datos certeros, ni datos digitalizados imposibilita determinar donde nos encontramos parados. Sin una cantidad especificada de empresas registradas a nivel nacional resulta casi imposible evidenciar los datos que estamos perdiendo. 
Más aún si tenemos en cuenta que sólo tres de las veinticuatro provincias de la Argentina solicitan la información del BF, que la CNV no tiene normas claras y una base unificada de todos aquellas sujetos que brindan la información, la tarea se vuelve por demás compleja.

\begin{tabular}{|c|c|}
\hline AVANCES & DESAFÍOS \\
\hline $\begin{array}{c}\text { Incorporación de un concepto más amplio } \\
\text { del BF } \\
\text { Solicitud de información en más } \\
\text { registros. } \\
\text { Primer registro digital en el ámbito de la } \\
\text { superintendencia de seguros de la nación. } \\
\text { Lanzamiento del Registro Nacional de } \\
\text { sociedades. } \\
\text { Prohibición de acciones al portador. } \\
\text { Prohibición del socio oculto, socio } \\
\text { aparente y socio del socio. }\end{array}$ & $\begin{array}{l}\text { De las } 24 \text { provincias, sólo } 3 \text { cuentan con } \\
\text { información de los BF aunque esos datos } \\
\text { no están digitalizados. } \\
\text { El Registro Nacional de Sociedades no } \\
\text { recaba información del BF } \\
\text { Se redujo la solicitud el control y } \\
\text { solicitud de información para las } \\
\text { sociedades extranjeras. } \\
\text { Escasa capacitación en la materia de BF } \\
\text { Falta de herramientas tecnológicas que } \\
\text { permitan digitalizar y procesar datos. } \\
\text { Imposibilidad de elaborar estadísticas. } \\
\text { Falta de información estandarizada } \\
\text { Eliminación del control de legalidad por } \\
\text { parte de los Registro Públicos. }\end{array}$ \\
\hline
\end{tabular}

Otro grave problema, es que algunos organismos como la IGJ, dan la posibilidad de que las empresas informen que no tiene beneficiarios finales. Estas opciones no colaboran en los procesos de transparencia. Como así tampoco que la poca información que se reúna de los beneficiarios finales se encuentre en soporte papel. Lo mismo ocurre con las Sociedades por Acciones Simplificadas donde los propios constituyentes pueden completar los formularios de solicitud de inscripción desconociendo el verdadero concepto de Beneficiario Final, ello conlleva a que se informen personas incorrectas, como un hijo, un vecino o un amigo.

A ello se le suma la falta de uniformidad y dispersión normativa, lo que puede terminar siendo funcional a quienes buscan ocultar a los verdaderos dueños.

El hecho de no contar con información de todo el país impide que se pueda contar con un sistema de alertas que permita detectar operaciones sospechosas que puedan estar encubriendo presuntas maniobras ilegales de dinero.

En efecto, tampoco existe una convalidación de los datos que se informan ya que no se cruzan con ningún dato de otro organismo como ser por ejemplo: el registro nacional de las personas. Ello nos permitiría saber, respecto de un individuo de nacionalidad argentina si se encuentra aún viva o no.

Respecto de los umbrales, existen muchos riesgos. Si el umbral es alto (entre un 20\% o $25 \%$, en adelante) se crea el riesgo de que los intereses o las titularidades significativas se dispersen en varias personas jurídicas y no deban informarse. Se crearán la participaciones societarias con umbrales que no excedan tal umbral y podrán ocultarse del registro de las autoridades de control.

No es posible identificar cual es la real voluntad política a seguir frente a la detección de los verdaderos dueños de las corporaciones, usando los registros y a todos los organismos de control del Estado como herramientas para combatir y disuadir el crimen organizado, la evasión de impuesto, la corrupción, la violación a los derechos humanos, entre otros.

No contar con información completa, precisa y oportuna de los beneficiarios finales de todas las personas y/o estructuras jurídicas nacionales y/o extranjeras que desarrollen sus actividades en suelo argentino, ralentiza muchísimo las investigaciones administrativas por parte 
de la UIF u otros organismos del estado, judiciales por parte del Poder Judicial y el Ministerio Público Fiscales, impide el cruce de información entre organismos nacionales y/o extranjeros. Es dable recordar que las organizaciones criminales no respetan fronteras y usualmente utilizan múltiples capas jurisdiccionales para desarrollar su actividad delictiva. El intercambio de información internacional es de gran importancia.

Aún queda un largo camino de análisis, parte del desafío será implementar y fomentar la elaboración de normas completas, con criterios unificados como así también analizar el uso de la información recolectada sobre los beneficiarios por parte del Poder Judicial y el Ministerio Público Fiscal.

Resulta imprescindible comprender que conocer quienes verdaderamente se encuentran detrás de las empresas pequeñas o grandes corporaciones resulta sustancial para descubrir lavadores de dinero, políticos corruptos, terroristas, traficantes de armas, traficantes de drogas, evasores de impuestos, entre otros, son ellos quienes utilizan estos canales societarios para mover su dinero mal habido. Y son las estructuras societarias, los bancos y otros profesionales dispuestos a hacer negocios, los que les permiten ocultar su identidad.

A ello que cabe agregar que el impacto más directo y completamente negativo que tales delitos y dicho ocultamiento generan en la sociedad civil, recae principalmente en los sectores más vulnerables. Ello por cuanto, el dinero fugado es dinero perdido del Estado Nacional, dinero que podría ser utilizado para la implementación de políticas públicas que los protejan y a la sociedad en su conjunto, salud, educación y seguridad son los pilares fundamentales que deben sostenerlo. Asimismo, cuando se trata de operaciones que extraen recursos del país el impacto es incluso mayor ya que presiona sobre la vulnerabilidad externa del país.

Los sectores más vulnerables son las principales víctimas de las organizaciones criminales, y el derecho no puede ser ajeno a ellos. Todo crecimiento en la materia permitirá avanzar en las investigaciones judiciales, en el dictado de sentencias con condenas a los efectivos criminales, en el decomiso de los bienes obtenidos y en su consecuente restitución a la sociedad como parte de un resarcimiento ante tanto daño causado.

Asimismo toda información que recaben los organismos de la Administración Pública obligados a hacerlo a través de un eficiente control de legalidad sobre el cumplimiento de las normas de transparencia hará que dicha información sea completa y certera, esto fortalecerá no sólo al Poder Judicial, al Ministerio Público Fiscal, a la Unidad de Información Financiera sino también al intercambio de información internacional en la materia. Las grandes estructuras y entramados societarios que intentan ocultar a los reales beneficiarios finales no respetan fronteras.

Hoy contamos con un Registro nacional obligado a reunir información de los beneficiarios finales de las empresas registradas en todo el país. Para ello necesita de la colaboración de los registros del todo el país, como así también contar con la posibilidad de que otros organismos de control también puedan remitir dicha información.

Esta materia debe ordenarse a nivel internacional en pos de armonizar normativas y lograr que los países cuenten con un registro público de beneficiarios finales para que el intercambio de información resulte completo, oportuno y global. 